\title{
MicroRNA-1 and MicroRNA-206 Regulate Skeletal Muscle Satellite Cell Proliferation and Differentiation by Repressing Pax7
}

\section{Citation}

Chen, Jian-Fu, Yazhong Tao, Juan Li, Zhongliang Deng, Zhen Yan, Xiao Xiao, and Da-Zhi Wang. 2010. microRNA-1 and microRNA-206 regulate skeletal muscle satellite cell proliferation and differentiation by repressing Pax7. The Journal of Cell Biology 190(5): 867-879.

\section{Published Version}

doi://10.1083/jcb.200911036

\section{Permanent link}

http://nrs.harvard.edu/urn-3:HUL.InstRepos:7351761

\section{Terms of Use}

This article was downloaded from Harvard University's DASH repository, and is made available under the terms and conditions applicable to Other Posted Material, as set forth at http:// nrs.harvard.edu/urn-3:HUL.InstRepos:dash.current.terms-of-use\#LAA

\section{Share Your Story}

The Harvard community has made this article openly available.

Please share how this access benefits you. Submit a story.

\section{Accessibility}




\title{
microRNA-1 and microRNA-206 regulate skeletal muscle satellite cell proliferation and differentiation by repressing Pax7
}

\author{
Jian-Fu Chen, ${ }^{1,2}$ Yazhong Tao, ${ }^{1,2}$ Juan Li, ${ }^{3}$ Zhongliang Deng, ${ }^{1,4}$ Zhen Yan, ${ }^{5}$ Xiao Xiao, ${ }^{3}$ and Da-Zhi Wang ${ }^{1,2,6}$ \\ 'McAllister Heart Institute, ${ }^{2}$ Department of Cell and Developmental Biology, and ${ }^{3}$ School of Pharmacy, University of North Carolina at Chapel Hill, Chapel Hill, NC 27599 \\ ${ }^{4}$ Department of Orthopedic Surgery, The Second Affiliated Hospital, Chongqing Medical University, Chongqing 400010, China \\ ${ }^{5}$ Department of Medicine, Duke University Medical Center, Durham, NC 27710 \\ ${ }^{\circ}$ Cardiovascular Research Division, Children's Hospital of Boston, Harvard Medical School, Boston, MA 02115
}

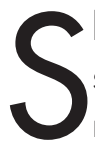
keletal muscle satellite cells are adult stem cells responsible for postnatal skeletal muscle growth and regeneration. Paired-box transcription factor Pax7 plays a central role in satellite cell survival, self-renewal, and proliferation. However, how Pax7 is regulated during the transition from proliferating satellite cells to differentiating myogenic progenitor cells is largely unknown. In this study, we find that miR-1 and miR-206 are sharply upregulated during satellite cell differentiation and downregulated after muscle injury. We show that miR-1 and miR-206 facilitate satellite cell differentiation by restricting

\section{Introduction}

Postnatal growth and regeneration of skeletal muscle mainly depend on adult muscle stem cells, named satellite cells. Satellite cells are characterized by the expression of the pairedbox transcription factor Pax7 (Buckingham, 2007; Kuang et al., 2008). Mouse genetics and cell culture studies reveal that Pax7 is required for satellite cell survival, proliferation, and to prevent precocious differentiation of myogenic progenitor cells (Oustanina et al., 2004; Kuang et al., 2006; Relaix et al., 2006; Zammit et al., 2006). Gene targeting studies show that satellite cells that lack Pax 7 and its close homologue, Pax3, die or differentiate into cartilage and other cell types (Relaix et al., 2005). However, Pax3 and Pax7 have been shown to function upstream of MyoD to activate skeletal muscle gene expression and to initiate the myogenesis program (Relaix et al., 2006). However, sustained expression of Pax7 in satellite cells delays the onset of myogenesis, and elevated expression of Pax7 in primary myoblasts

Correspondence to Da-Zhi Wang: dwang@enders.tch.harvard.edu Abbreviations used in this paper: bFGF, basic FGF; DM, differentiation medium; EDL, extensor digitorum longus; $G M$, growth medium; IP, intraperitoneal; miRNA, microRNA; MyHC, myosin heavy chain; UTR, untranslated region. their proliferative potential. We identify Pax7 as one of the direct regulatory targets of miR-1 and miR-206. Inhibition of miR-1 and miR-206 substantially enhances satellite cell proliferation and increases Pax7 protein level in vivo. Conversely, sustained Pax7 expression as a result of the loss of miR-1 and miR-206 repression elements at its $3^{\prime}$ untranslated region significantly inhibits myoblast differentiation. Therefore, our experiments suggest that microRNAs participate in a regulatory circuit that allows rapid gene program transitions from proliferation to differentiation. inhibits the expression of MyoD, preventing myogenin induction and muscle terminal differentiation (Olguin and Olwin, 2004; McFarlane et al., 2008). These studies suggest that Pax7 plays a dual role in satellite cell fate maintenance and myogenic progenitor cell differentiation. These observations further imply that precise regulation of $\operatorname{Pax} 7$ is crucial for satellite cell transition from proliferation/self-renewal to differentiation.

MicroRNAs (miRNAs) are a class of $\sim 22$ nucleotide noncoding RNAs that regulate gene expression at the posttranscriptional level. The involvement of miRNAs in muscle biology has recently been reported. miRNAs regulate the expression of transcription factors and signaling mediators important for cardiac and skeletal muscle development and function (Callis and Wang, 2008; van Rooij et al., 2008). Aberrant miRNA expression has been observed in muscle diseases, including cardiac and skeletal muscle hypertrophy, heart failure, and muscular

(C) 2010 Chen et al. This article is distributed under the terms of an AttributionNoncommercial-Share Alike-No Mirror Sites license for the first six months after the publication date (see http://www.rupress.org/terms). After six months it is available under a Creative Commons License (Attribution-Noncommercial-Share Alike 3.0 Unported license, as described at http://creativecommons.org/licenses/by-nc-sa/3.0/). 
dystrophy (Eisenberg et al., 2007; Tatsuguchi et al., 2007; Thum et al., 2007). We have previously shown that the expression of muscle-specific miR-1 and miR-133 is induced during skeletal muscle differentiation. We further demonstrated that miR-1 and miR-133 play central regulatory roles in myoblast proliferation and differentiation (Chen et al., 2006). Interestingly, miR-1 and miR-133 are also important regulators of cardiomyocyte differentiation and heart development (Zhao et al., 2007; Ivey et al., 2008).

As stem cells differentiate, they turn on lineage-specific genes while down-regulating stem cell maintenance genes in response to appropriate cues (Jaenisch and Young, 2008; Rossant, 2008). Although these maintenance genes are regulated mainly at the transcriptional level, remaining transcripts that were highly expressed in the previous stage need to be effectively silenced for optimal transition from one gene program to another. In this sense, miRNAs are well suited for clearing these residual messages. Genetic studies on the components of the miRNA biogenesis pathway indicate that Dicer and miRNAs are essential for embryonic stem cell survival and differentiation (Murchison et al., 2005; Wang et al., 2007). It was recently reported that a skin miRNA (miR-203) promotes the differentiation of skin progenitor cells by restricting cell proliferation and inducing cell cycle exit. miR-203 achieved this function by repressing p63, a key factor for skin stem cell fate maintenance (Yang et al., 1999; Senoo et al., 2007; Yi et al., 2008). Interestingly, muscle-specific miR-1 and miR-133 appear to play a role in cardiac differentiation from embryonic stem cells (Ivey et al., 2008). Together, these studies indicate that miRNAs could be previously unrecognized regulators of muscle progenitor cell proliferation, fate specification, and differentiation.

In this paper, we study the function of miRNAs in skeletal muscle satellite cells and their derived myogenic progenitor cells. We find that miR-1 and miR-206 are highly induced during satellite cell and primary myoblast differentiation. We show that miR-1 and miR-206 promote satellite cell differentiation and restrict their proliferative potential. We further identify Pax7 as one of the direct regulatory targets of miR-1 and miR-206. In vivo knockdown of endogenous miR-1 and miR-206 in neonatal mouse skeletal muscle substantially enhances satellite cell proliferation and increases Pax 7 protein level. In contrast, loss of miR-1 and miR-206 repression leads to sustained Pax7 expression, which results in inhibition of myogenic progenitor cell differentiation. Together, our experiments uncover a key role of miRNAs in skeletal muscle satellite cells and myogenic progenitor cells in which miR-1 and miR-206 participate in a regulatory circuit that facilitates gene program transition from proliferation to differentiation.

\section{Results}

miRNAs are required for proper differentiation of satellite cells

To study the potential involvement of miRNAs in muscle stem cell differentiation, we first established a satellite cell in vitro differentiation system. Mouse skeletal muscle satellite cells were isolated from single myofibers of hind leg muscle of young adult mice. We carefully tested and compared two protocols for satellite cell isolation according to previous studies (see Materials and methods; Rosenblatt et al., 1995; Conboy and Rando, 2002; Shefer and Yablonka-Reuveni, 2005; Shinin et al., 2006). In our experiments, the protocol using extensor digitorum longus (EDL) muscle-derived myofibers yielded the purest single myofiber and satellite cell preparations. Satellite cell preparations were consistently $>90 \%$ pure, as indicated by the expression of Pax7 and $\alpha 7$-integrin and the absence of myogenin or myosin heavy chain (MyHC) expression (Fig. S1). Therefore, in this study, we adopted the satellite cell isolation protocol from single myofibers of EDL muscle. Isolated satellite cells were maintained on collagen-coated plates, and they continued to proliferate without differentiation when cultured in the presence of basic FGF (bFGF). However, shortly after removal of bFGF and cultured in low-serum medium (differentiation condition), satellite cells quickly exited the cell cycle and initiated myogenic differentiation, a process that faithfully mimics the in vivo myogenesis process (Clegg et al., 1987; Templeton and Hauschka, 1992; Sabourin et al., 1999). The differentiation capacity of isolated satellite cells was confirmed by the expression of $\mathrm{MyHC}$, a skeletal muscle terminal differentiation marker, upon differentiation induction (Fig. 1 A).

To assess the role of miRNAs in satellite cells, we isolated and cultured satellite cells from Dicer ${ }^{\text {flox/flox }}$ mice, in which exons 22 and 23 of the Dicer gene had been flanked by loxP sequences (Murchison et al., 2005; Chen et al., 2008). Dicer encodes an RNase III endonuclease responsible for miRNA maturation; therefore, deletion of Dicer leads to depletion of all mature and functional miRNAs (Bernstein et al., 2001; Grishok et al., 2001). We infected the Dicer ${ }^{\text {flox/flox }}$ satellite cells with adenoviruses that expressed either the Cre recombinase (Ad-Cre) or the controls LacZ- (Ad-LacZ) or GFP- (Ad-GFP; Fig. 1 B). $48 \mathrm{~h}$ after Ad-Cre infection, Dicer was deleted, and the expression of miRNAs was significantly decreased, as demonstrated by the decreased expression of miR-1, one of the most abundant miRNAs in skeletal muscle myoblasts and myotubes (Fig. 1, $\mathrm{C}$ and D). To assess the differentiation potential of the Dicernull satellite cells, we switched the Ad-Cre-infected Dicer ${ }^{\text {flox/flox }}$ satellite cells to differentiation medium (DM; Sabourin et al., 1999). Interestingly, we observed a significant loss of cell viability in Dicer-null satellite cells upon differentiation induction, as indicated by the increase of TUNEL-positive cells (Fig. S2, $\mathrm{A}$ and B). These observations are consistent with a previous study demonstrating that Dicer and miRNAs are required for stem cell survival (Bernstein et al., 2003).

We next investigated the effects of the Dicer mutation on satellite cell differentiation potential. We examined the expression of Pax7, myogenin, and MyHC in Ad-Cre or Ad-LacZ-transduced satellite cells under growth or differentiation conditions. Under the growth condition, in which both the Dicer-null and wild-type satellite cells were maintained at an undifferentiated state, we observed essentially no difference in Pax7 expression level (unpublished data). $12 \mathrm{~h}$ after being switched to the DM, satellite cells started to differentiate. We detected similar myogenin expression in both Dicer-null and wild-type satellite cells (unpublished data). These observations 


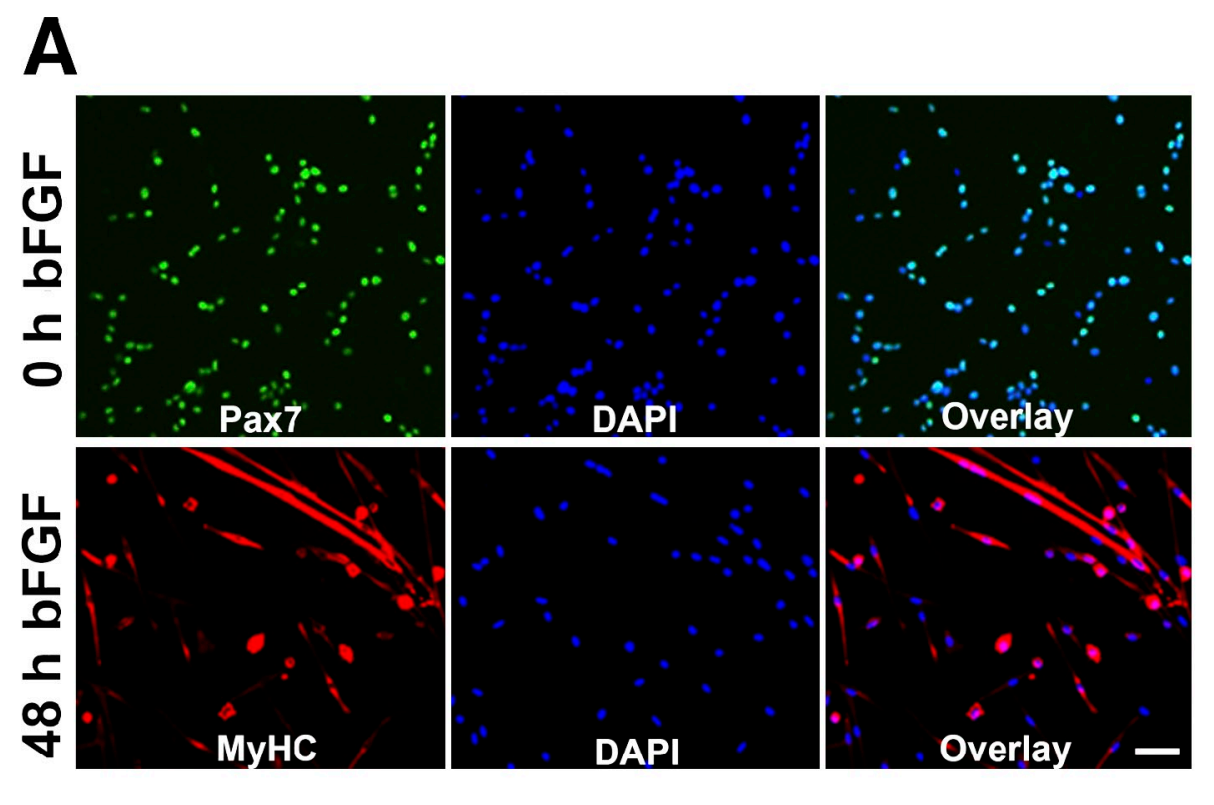

\section{B}
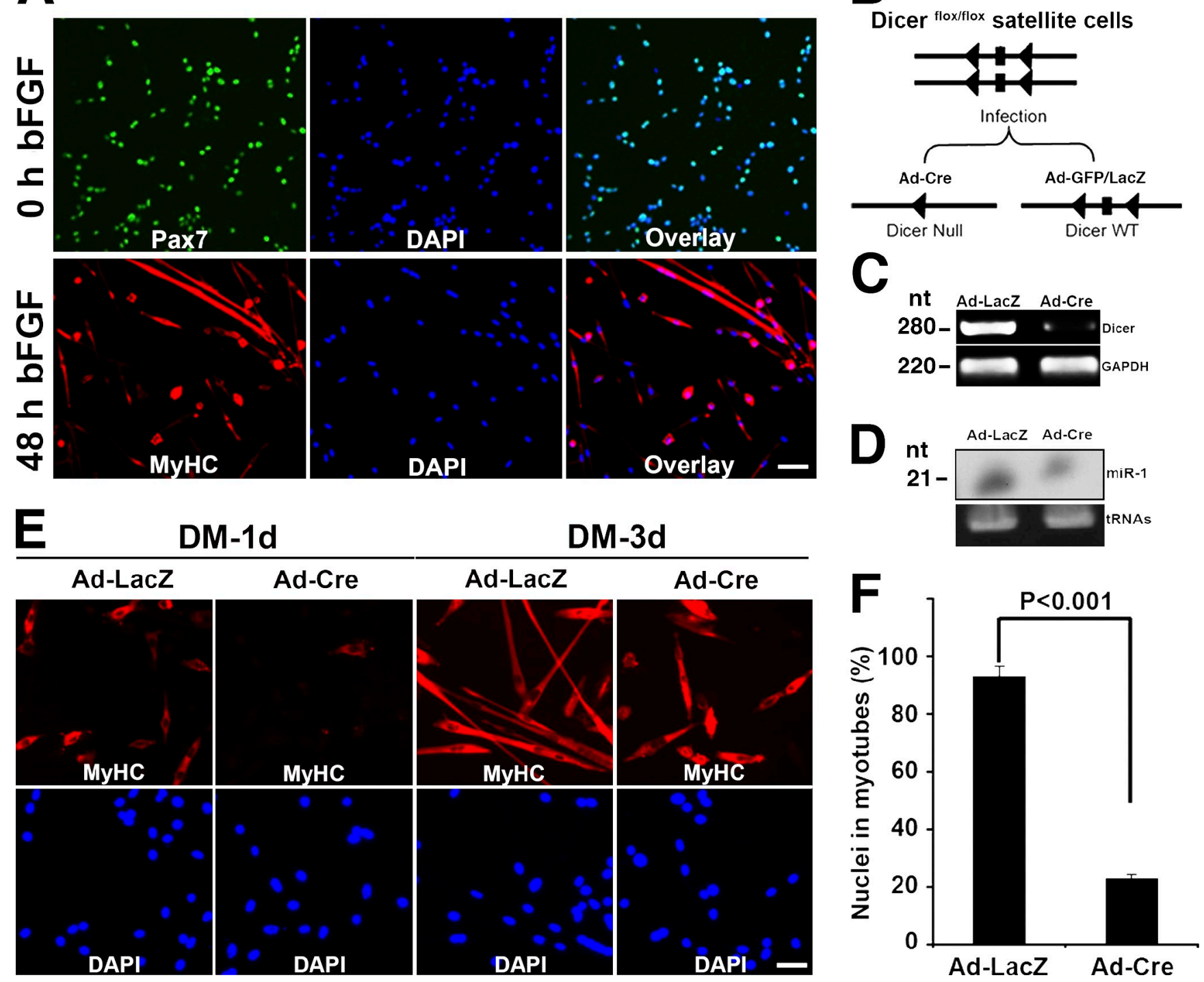

Figure 1. miRNAs are required for skeletal muscle satellite cell differentiation in vitro. (A) Isolation and differentiation induction of satellite cells. Satellite cells under growth (O h bFGF) or differentiation condition (48 h bFGF) were fixed and stained with antibodies against Pax7 or MyHC. DAPI-stained nuclei. Bars, $40 \mathrm{\mu m}$. (B) Scheme for the generation of Dicer-null satellite cells. LoxP sites (triangles) allow the deletion of Dicer after the infection of an adenoviral vector expressing Cre recombinase (Ad-Cre). Adenovirus-expressing GFP (Ad-GFP) or LacZ (Ad-LacZ) served as the control. WT, wild type. (C) RT-PCR analyses of Dicer expression using RNAs isolated from Ad-Cre or Ad-LacZ-infected Dicerflox/flox satellite cells at $48 \mathrm{~h}$ after infection and differentiation induction in DM. GAPDH was used as a loading control. (D) Northern blot analyses of miR-1 expression using the same set of RNAs as C. tRNAs were used as a loading control. (E) Satellite cells infected with Ad-LacZ or Ad-Cre were switched into DM for 1 (DM-ld) or $3 d$ (DM-3d), and myogenic differentiation was detected by immunostaining for MyHC. DAPl-stained nuclei. Bars, 20 jm. (F) Quantification of fusion event of myoblasts infected with Ad-LacZ or Ad-Cre at $3 \mathrm{~d}$ in DM. The fusion index is calculated as the percentage of nuclei in fused myotubes out of the total nuclei for each microscopic field. Myotubes with two or more nuclei were defined as fused myotubes. nt, nucleotide. Error bars indicate SEM of 10 microscopic fields from three independent experiments.

suggest that miRNAs are not required for the initiation of satellite cell differentiation. $24 \mathrm{~h}$ after switching to DM, control wild-type satellite cells further differentiated into myocytes, as indicated by the expression of MyHC proteins. However, very little MyHC expression was detected in Dicer-null cells (Fig. $1 \mathrm{E}$ ). $3 \mathrm{~d}$ after differentiation induction, robust myogenic differentiation was observed in control satellite cells, as demonstrated by multinucleated myotube formation and $\mathrm{MyHC}$ expression. However, Dicer-null satellite cells were unable to complete myogenic differentiation, as indicated by a much-reduced MyHC expression (Fig. 1 E) and absence of multinucleated myotube formation (Fig. 1, E and F). These data suggest that Dicer is essential for both survival and terminal differentiation of skeletal muscle satellite cells.

\section{miRNA expression during satellite cell differentiation and skeletal \\ muscle regeneration}

To define the signature of miRNA expression in satellite cells and myogenic progenitor cells and to identify miRNAs that are responsive to satellite cell differentiation, we performed miRNA microarray analyses on satellite cells, which were grown in 

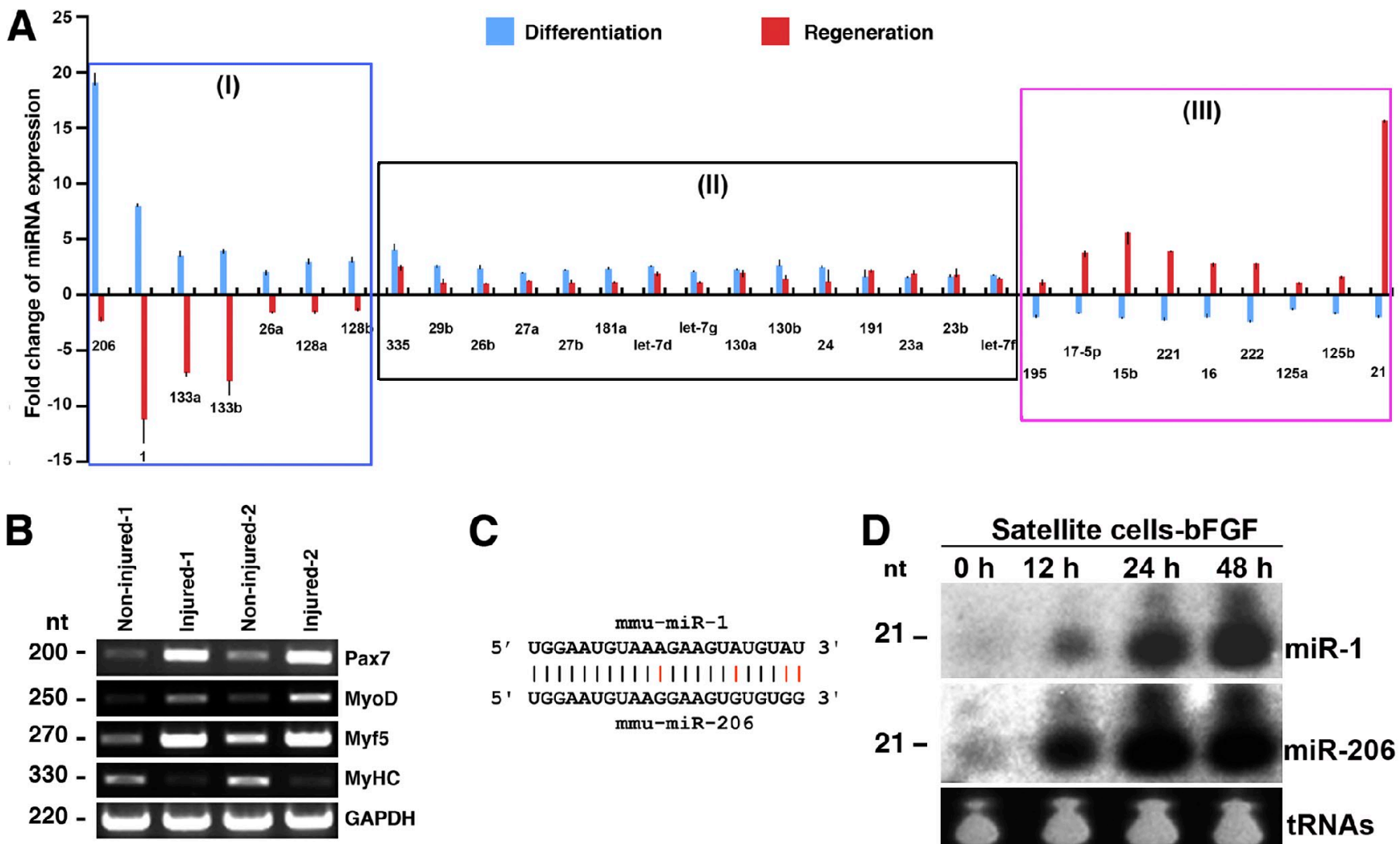

C

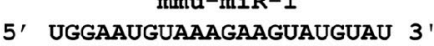

|||||||||||||||||||||| 5 ' UGgaAUGUAAGGaAgUGUGUGG 3 ' mmu-miR-206

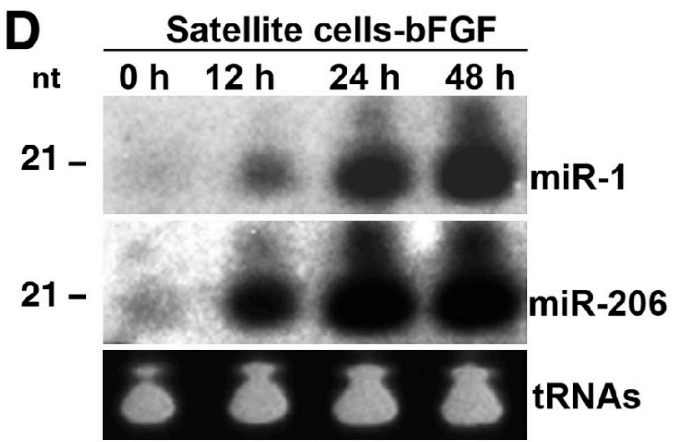

$\mathbf{E}$ miR-1 sensor miR-1 sensor-M

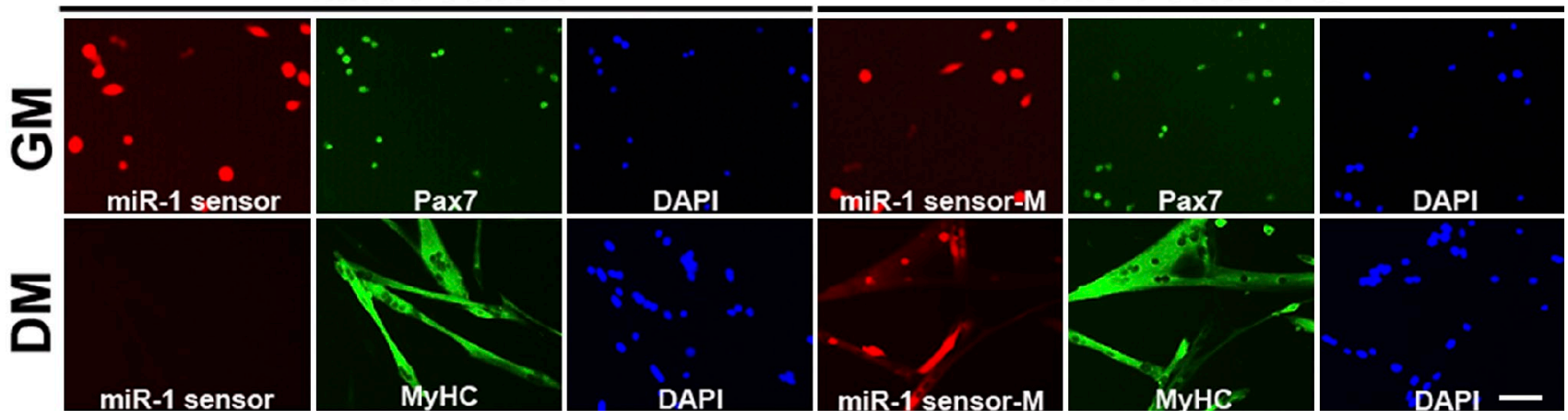

Figure 2. miRNA expression pattern during satellite cell differentiation and adult skeletal muscle regeneration. (A) Microarray analyses of miRNA expression in differentiating satellite cells or regenerating skeletal muscle. Bar graph indicates the fold change in miRNA expression during satellite cell differentiation and muscle regeneration compared with their respective controls. Group I represents miRNAs induced in differentiating satellite cells and repressed in regenerating muscle. Group II miRNAs are moderately induced in both differentiating satellite cells and regenerating muscle. miRNAs in group III are repressed in differentiating satellite cells and induced in regenerating muscle. Data represent two independent experiments in triplicate. $P<0.05$. (B) RT-PCR analyses of RNAs isolated from noninjured or injured skeletal muscle for the indicated genes. GAPDH served as a loading control. (C) Alignment of mouse miR-1 and miR-206 sequences. (D) Northern blot analyses of miR-1 and miR-206 expression using RNAs isolated from satellite cells at different time points of differentiation induction. tRNAs were used as a loading control. (E) Immunofluorescence of satellite cells expressing a sensor construct containing the miR-1 complementary site (miR-1 sensor) or the mutated miR-1 complementary site (miR-1 sensor M) in GM or DM for 72 h. Note that the expression of miR-1 was inversely correlated with dsRed. miR-1 sensor, but not the mutant miR-1 sensor, was completely silenced in the differentiation condition in which miR-1 was highly expressed. Satellite cell identity and their differentiation status were confirmed by the expression of Pax7 and MyHC, respectively. DAPIcounterstained nuclei. nt, nucleotide. Bar, $40 \mu \mathrm{m}$.

growth medium (GM) and satellite cells that had been switched to DM for $1 \mathrm{~d}$ to induce differentiation (Fig. $2 \mathrm{~A}$ ). We also used RNA from normal adult mouse skeletal muscle as well as from injured muscle $3 \mathrm{~d}$ after cardiotoxin injection to identify the miRNA expression signature during muscle regeneration in vivo. It has been well established that injury stimulates satellite cells to reenter the cell cycle and undergo extensive proliferation and differentiation (Morgan and Partridge, 2003; Yan et al., 2003).
Consistent with a previous study (Yan et al., 2003), molecular marker analyses confirmed that $3 \mathrm{~d}$ after cardiotoxin injection corresponds to a stage of active satellite cell proliferation (Fig. 2 B). miRNA microarray data revealed that a subset of miRNAs, including miR-1, miR-206, miR-133a, and miR-133b, were highly induced during satellite cell differentiation. Intriguingly, the expression of these miRNAs was markedly down-regulated in injured skeletal muscle where active muscle regeneration was 
occurring (Fig. 2 A, group I). Conversely, another set of miRNAs were highly induced in regenerating skeletal muscle, and their expression decreased in differentiating satellite cells. These included miR-21 and others (Fig. 2 A, group III). In addition, we found that the expression of some miRNAs was moderately increased in both differentiating satellite cells and regenerating skeletal muscle (Fig. 2 A, group II). These observations suggest that miRNAs are likely involved in the process of satellite cell proliferation, differentiation, and skeletal muscle regeneration.

Based on their high expression levels and dynamic change during satellite cell differentiation and muscle regeneration, we decided to focus on miR-1 and miR-206. Both miR-1 and miR-206 belong to the miRNA family of miR-1, and they share a high homology in their sequences (Griffiths-Jones, 2004). Both miR-1 and miR-206 contain identical "seed" sequences (bases 2-8 of the $5^{\prime}$ end of the miRNA), suggesting that they likely regulate the same or very similar target genes (Fig. 2 C). The induction of miR-1 and miR-206 expression during satellite cell differentiation was further confirmed by miRNA Northern blot analyses (Fig. 2 D). To precisely monitor the expression and action of these miRNAs at the single cell level in satellite cells, we used an miR-1 sensor, in which the complementary sequence for miR-1 was cloned downstream of a dsRed coding sequence (Chen et al., 2006). As a control sensor, the miR-1-binding sequence was mutated (miR-1 sensor M). When maintained in GM, similar dsRed expression levels were detected in both miR-1 sensorexpressed cells (miR-1 sensor) and control cells (miR-1 sensor $\mathrm{M}$ ), indicating that miR-1 actually was nearly undetectable in undifferentiated satellite cells (Fig. 2 E, top). However, when satellite cells were switched into DM to induce to differentiation, the expression of dsRed was extinguished in miR-1 sensor cells, whereas control cells still exhibited strong dsRed (Fig. 2 E, bottom). These data further demonstrate that miR-1 actually is highly induced during satellite cell differentiation.

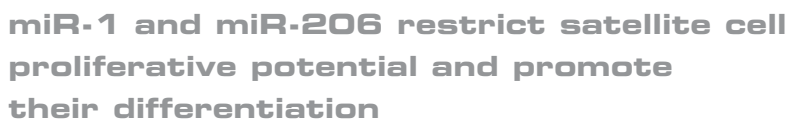

The sharp induction of miR-1 and miR-206 expression during the transition of satellite cells from proliferation to differentiation, as well as their decreased expression in regenerating skeletal muscle, prompted us to investigate the role of these miRNAs in satellite cells and satellite cell-derived myogenic progenitor cells. We hypothesized that miR-1 and miR-206 repress the satellite cell proliferation program, thus facilitating myogenic differentiation. To test this hypothesis, we prematurely overexpressed miR-1, miR-206, or both in isolated satellite cells using adenoviruses. We validated the expression of miR-1, miR-206, or both using Northern blot analyses (Fig. S2 and not depicted). BrdU incorporation experiments were performed to assess the proliferation of satellite cells. miR-1 and miR-206 strongly inhibited satellite cell proliferation, as indicated by significantly less BrdU incorporation in miRNA-overexpressing satellite cells in comparison with control cells ( $n=3$ independent isolation and infection; Fig. 3, A and B).

To further characterize the inhibition of satellite cell proliferative potential by miR-1 and miR-206, we performed satellite cell colony formation assays (Montarras et al., 2005; Shinin et al., 2006). We applied a retroviral expression system modified from previous studies (Miller and Rosman, 1989; Grez et al., 1990), in which genomic sequences encoding miR-1 and miR-206 were cloned upstream of a GFP cassette and were under the control of the cytomegalovirus promoter, which directs the expression of miR-1, miR-206, and GFP simultaneously (Fig. S2 E). We also validated the expression and activity of these miRNAs using both RNA Northern blot analyses and miR-1 sensor (Fig. S2 and not depicted). Indeed, overexpression of miR-1 and miR-206 significantly inhibits colony formation by satellite cells. Approximately $18 \mathrm{~h}$ after the retroviral infection, a similar number of colonies and a similar number of cells within individual colonies were observed in the control and miR-1- and miR-206infected satellite cells. At this stage, the majority of GFPpositive colonies exhibited single- or two-cell pattern when plated at a low density (Fig. 3, D and E). However, $72 \mathrm{~h}$ after the retroviral infection, significantly fewer colonies were formed in miR-1- and miR-206-infected satellite cells compared with the control (Fig. 3, C-E). In addition, we found that $\sim 50 \%$ of colonies contained $>20$ cells in the control satellite cells. In contrast, the number of colonies that contained $>20$ cells were much less in miR-1- and miR-206-infected satellite cells (Fig. 3 E). These results indicate that miR-1 and miR-206 restrict satellite cell proliferation and colony formation.

To study the effect of miR-1 and miR-206 on satellite cell differentiation, we performed immunofluorescent staining using an antibody against $\mathrm{MyHC}$ at different time points after the initiation of satellite cell differentiation induction. Indeed, miR-1 and miR-206 accelerated satellite cell differentiation (Fig. 3 F). Quantitative analyses demonstrated that these changes are statistically significant (Fig. $3 \mathrm{G}$ ). Together, these data suggest that miR-1 and miR-206 restrict satellite cell proliferative potential and positively regulate satellite cell differentiation.

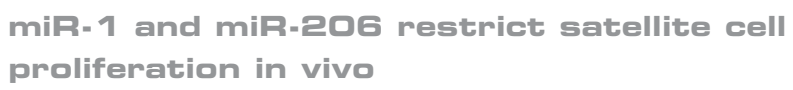

To investigate whether miR-1 and miR-206 also restrict the proliferative potential of satellite cells in vivo, we knocked down both miR-1 and miR-206 in the skeletal muscle of neonatal mice using miRNA antagomirs (Krutzfeldt et al., 2005; Yi et al., 2008). Administration of antagomir-1 and -206, but not PBS or mut-antagomir-1 and -206 (in which four mismatch mutations were introduced into each miRNA sequence), resulted in a profound decrease in the endogenous expression level of miR-1 and miR-206 in skeletal muscle (Fig. 4 A). Both intraperitoneal (IP) injection and intramuscular injection of antagomir-1 and -206 markedly abolished endogenous miR-1 and miR-206 in skeletal muscle (Fig. 4 and Fig. S3 A). The expression of miR-1 was also dramatically abolished in the heart after IP injection (but not intramuscular injection) of antagomir-1 (unpublished data). Most importantly, the expression level of miR-133, which is clustered with miR-1 in the mouse genome and is normally cotranscribed with miR-1, was unaffected by antagomir-1 and -206 under the same conditions (Fig. $4 \mathrm{~A}$ and Fig. S3), indicating that the action of antagomirs is highly specific. 


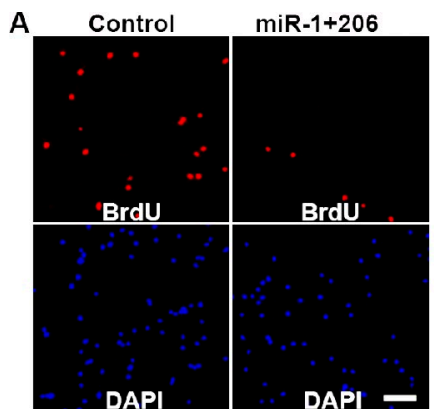

$E$

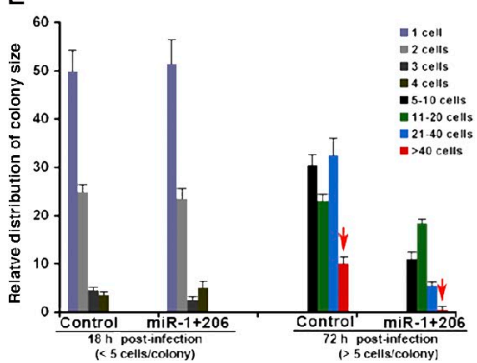

B

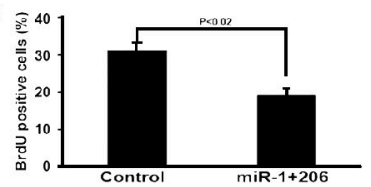

C

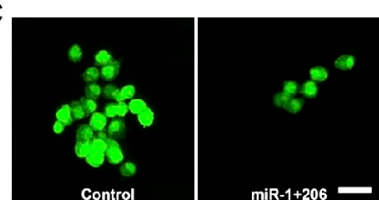

D

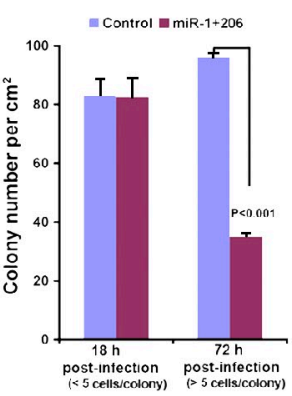

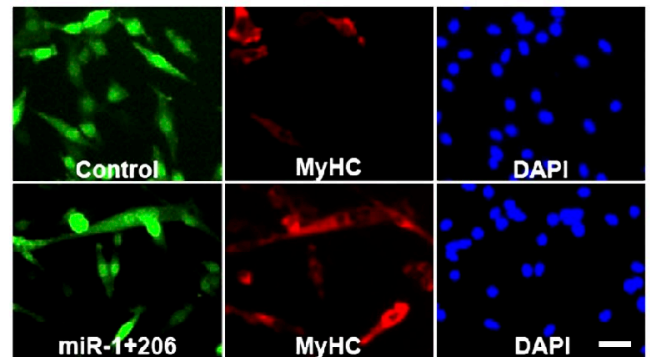

G

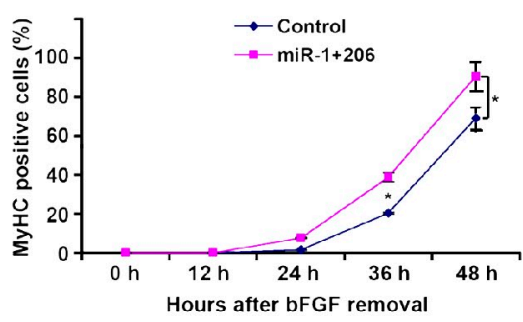

Figure 3. miR-1 and miR-206 restrict the proliferative potential of satellite cells and enhance their differentiation. (A) Satellite cells were infected with either Ad-miR-1+206 or Ad-GFP (control) and pulsed with $10 \mu \mathrm{M} \mathrm{BrdU} \mathrm{for} 1.5 \mathrm{~h}$. $12 \mathrm{~h}$ later, cell proliferation was determined by immunostaining using antibody against BrdU (red). DAPI-counterstained nuclei. Bar, 40 um. (B) Quantification of BrdU labeling experiments. The BrdU-positive cells percentage was calculated as the percentage of BrdU-positive cells out of total number of cells indicated by DAPI-positive staining for each microscopic field. P < 0.02 . Error bars indicate SEM of 10 microscopic fields from three independent experiments. (C) Satellite cell colony formation assays. Satellite cells were infected with retroviral vectors expressing miR-1 and miR-206 (miR-1+206) or mutated miR-1 and miR-206 (control) and colony size determined. Note the small size of colony expressing miR-1 and miR-206 (miR-1+206) compared with controls $72 \mathrm{~h}$ after retroviral infection. Bar, 20 rm. (D and E) Quantification of satellite cell colony formation assay results. The colony numbers (D) and the distribution of different colony size (E) were measured 18 and $72 \mathrm{~h}$ after retroviral vector infection. For colony size measurement at $72 \mathrm{~h}$, only colonies containing more than five cells were counted. Data represent the mean \pm SD from two independent experiments. (E) Red arrows indicate colonies that contain $>40$ cells. (F) Satellite cells infected with retroviral vector expressing miR-1 +206 or GFP (control) were switched to DM for 48 h, and myogenic differentiation was determined by immunostaining for MyHC. Green, infected cells; red, MyHC. DAPI (blue)-counterstained nuclei. Bar, $20 \mu \mathrm{m}$. (G) Quantification of satellite cell differentiation at different time points after miR-1+206 overexpression. Data represent the mean \pm SD from three independent experiments. ${ }^{*}, P<0.05$.

We examined the effects of miR-1 and miR-206 knockdown on mouse skeletal muscle development and satellite cell proliferation. We first performed BrdU incorporation experiments to label proliferating cells. Quantitative analyses revealed a significant increase in BrdU-positive cells in antagomir-1and -206-treated skeletal muscle compared with control mutantagomir-1- and -206-treated samples (Fig. 4, B and C), indicating that the knockdown of endogenous miR-1 and miR-206 indeed enhanced muscle cell proliferation. Consistent with the aforementioned observation, we found substantially more phospho-histone $\mathrm{H} 3$-positive cells in antagomir-1- and -206-treated muscle than in control muscle (Fig. 4, D and E). To further confirm the satellite cell identity of these proliferating cells in skeletal muscle, we examined the expression of Pax7, a well-defined marker for satellite cells, and found a significant increase in Pax7-positive cells in antagomir-1- and -206-treated skeletal muscle (Fig. 4, F and G; and Fig. S3). Quantitative analyses indicate that $88 \%$ of BrdU-positive cells were also positive for Pax7 in antagomir-1- and -206-treated skeletal muscle (Fig. S3 D). These in vivo results, together with our previous findings in which miR-1 and miR-206 inhibit satellite cell colony formation and proliferation in vitro, further support the view that miR-1 and miR-206 are key regulators of satellite cell proliferation.

\section{Pax 7 is a direct regulatory target of miR-1 and miR-206 during satellite cell differentiation}

Pax7, a paired-box transcription factor, has been well established as a key regulator of satellite cell survival, self-renewal, and proliferation (Oustanina et al., 2004; Zammit et al., 2004; Relaix et al., 2006; McFarlane et al., 2008). The observation that overexpression of miR-1 and miR-206 in satellite cells dramatically inhibited colony formation and decreased the size of individual colonies prompted us to further examine the expression of Pax7 in miR-1- and miR-206-overexpressed satellite cells. Indeed, we observed an inverse correlation between the expression level of miR-1/miR-206 and Pax7 protein in satellite cell colonies (Fig. 5 A and Fig. S4), suggesting that miR-1 and miR-206 may participate in the repression of $\operatorname{Pax} 7$ protein expression. Parallel up-regulation of miR-1 and miR-206 and down-regulation of Pax7 during satellite cell differentiation led us to hypothesize that miR-1 and miR-206 directly inhibit Pax7 gene expression.

To test this hypothesis, we searched for miR-1 and miR-206 regulatory targets. Indeed, two putative miR-1- and miR-206binding sites were identified in the $3^{\prime}$ untranslated region (UTR; of Pax7 mRNA; Fig. S5). Next, we performed luciferase reporter assays using a partial sequence of the Pax $73^{\prime}$-UTR 


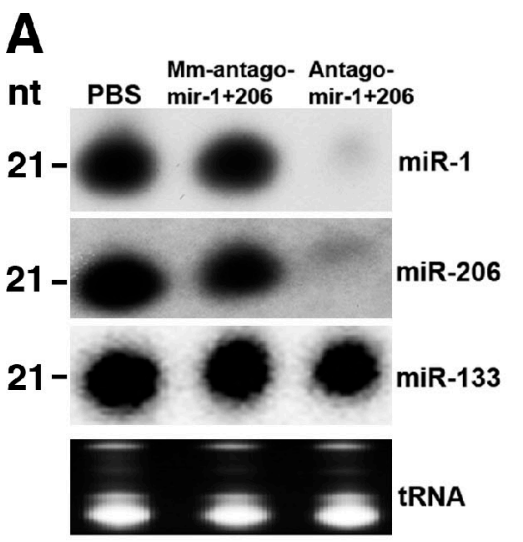

D

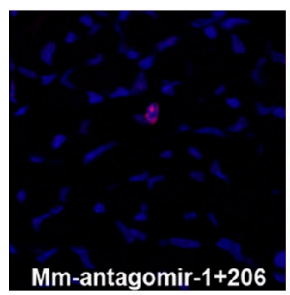

B
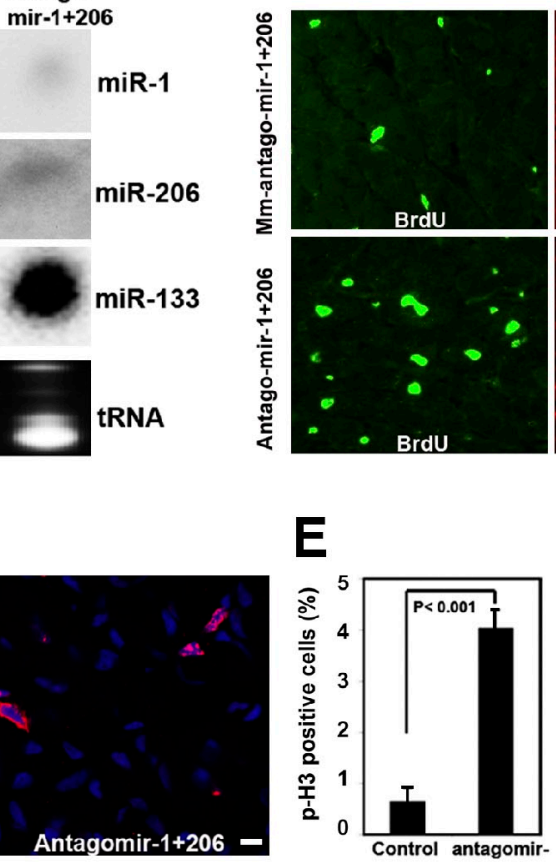

E

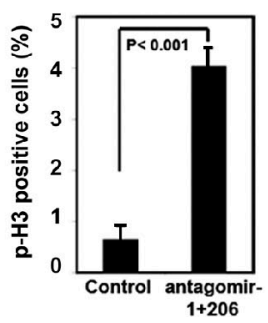

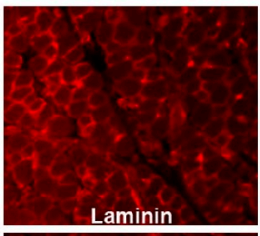
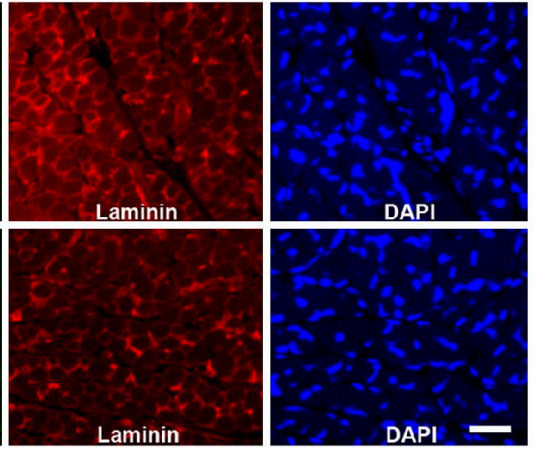

$\mathbf{F}$

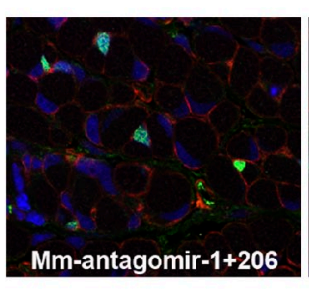

C

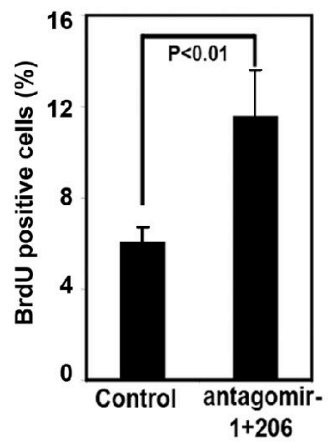

G

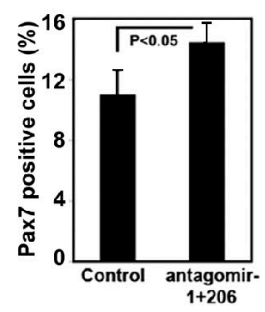

Figure 4. Knockdown of miR-1 and miR-206 increases the proliferation of satellite cells in vivo. (A) Northern blot analyses of total RNAs isolated from skeletal muscle $24 \mathrm{~h}$ after the last injection of RNA antagomirs against miR-1 and miR-206 (antagomir-1 +206). Muscle injected with PBS or mutated miR-1 and miR-206 antagomirs (mut-antagomir-1+206) were used as controls. tRNAs were used as a loading control. nt, nucleotide. (B) Confocal microscopic images of skeletal muscle $4 \mathrm{~h}$ after BrdU labeling from postnatal mice treated with antagomir-1+206 or mut-antagomir-1+206 (serves as a control). Cell proliferation was determined by anti-BrdU antibody (green), laminin (red)-marked cell surface, and DAPI (blue)-counterstained nuclei. Bar, 20 um. (C) Quantitative measurement of BrdU-positive cells from experiments in B. The BrdU-positive cells percentage was calculated as the percentage of BrdU-positive cells out of the total number of cells indicated by DAPI-positive staining for each microscopic field. Error bars indicate SEM of 10 microscopic fields from three independent experiments. $P<0.01$. (D) Confocal microscopic images of skeletal muscle from mice treated with antagomir-1+206 or mut-antagomir- $1+206$ (controls). Anti-phospho-histone H3 antibody (red) visualized mitotic cells. DAPI (blue)-counterstained nuclei. Bar, $10 \mu \mathrm{m}$. (E) Quantitative measurement of phospho-histone $\mathrm{H} 3$ (p-H3)-positive cells from experiments in D. The phospho-histone H3-positive cells percentage was calculated as the percentage of phospho-histone H3-positive cells out of the total number of cells indicated by DAPI-positive staining for each microscopic field. Error bars indicate SEM of 10 microscopic fields from three independent experiments. $P<0.001$. (F) Merged confocal microscopic images of skeletal muscle from antagomir- $1+206$ or mut-antagomir-1+206-treated mice. Anti-Pax7 antibody-labeled satellite cells (green). Laminin (red)-outlined cell surface and DAPI (blue)-counterstained nuclei. Bar, 10 um. (G) Quantitative measurement of Pax7-positive cells from experiments in F. The Pax7-positive cells percentage was calculated as the percentage of Pax7-positive cells out of the total number of cells indicated by DAPI-positive staining for each microscopic field. Error bars indicate SEM of 10 microscopic fields from three independent experiments. $P<0.05$.

that contained both miR-1- and miR-206-binding sites (Fig. S5). Not surprisingly, miR-1, miR-206, or both strongly repressed Pax7 3'-UTR luciferase activity (Fig. 5 B). Introduction of mutations into these two miRNA-binding sites completely abolished miR-1 and miR-206-mediated repression, demonstrating the specificity of repression (Fig. 5 B). Furthermore, we tested whether miR-1 and miR-206 could reduce the endogenous Pax7 protein level in isolated satellite cells. Western blot analyses clearly demonstrate that miR-1 and miR-206 overexpression reduced Pax 7 protein expression (Fig. 5 C). Interestingly, although we observed a significant repression of Pax7 protein by miR-1 and miR-206, the expression level of Pax7 mRNA only decreased slightly (Fig. 5 C), indicating that a posttranscriptional regulation of $\mathrm{Pax} 7 \mathrm{ex}-$ pression is likely involved. Finally, we found that the Pax7 protein level was down-regulated during satellite cell differentiation (Fig. 5 D), which is consistent with previous observations (Olguin et al., 2007). Together, these results demonstrate that miR-1 and miR-206 directly regulate Pax7 protein expression posttranscriptionally.
miR-1 and miR-206-mediated repression of $P a x 7$ is essential for myogenic progenitor cell differentiation

Pax7 plays a central role in satellite cell self-renewal and the initiation of the myogenic program (Oustanina et al., 2004; Zammit et al., 2004; Relaix et al., 2006). Intriguingly, it has also been observed that sustained expression of $\operatorname{Pax} 7$ in myogenic progenitor cells significantly represses myogenic terminal differentiation (Olguin and Olwin, 2004; McFarlane et al., 2008). We hypothesized that miR-1 and miR-206-mediated repression of Pax7 protein level through its $3^{\prime}$-UTR might be essential for the transition of myogenic progenitor cells from proliferation to differentiation. To test this hypothesis, we built two Pax7 expression constructs in which the $3^{\prime}$-UTR was either included or excluded (referred to as Pax7-UTR and Pax7, respectively); we also built another Pax7 expression construct in which both the miR-1 and miR-206 targeting sites in its $3^{\prime}$-UTR were mutated (referred to as Pax7-UTR-M; Fig. 6 A). We examined the effects of these Pax7 expression constructs on Pax7 protein expression and myoblast differentiation. To perform these experiments, we 

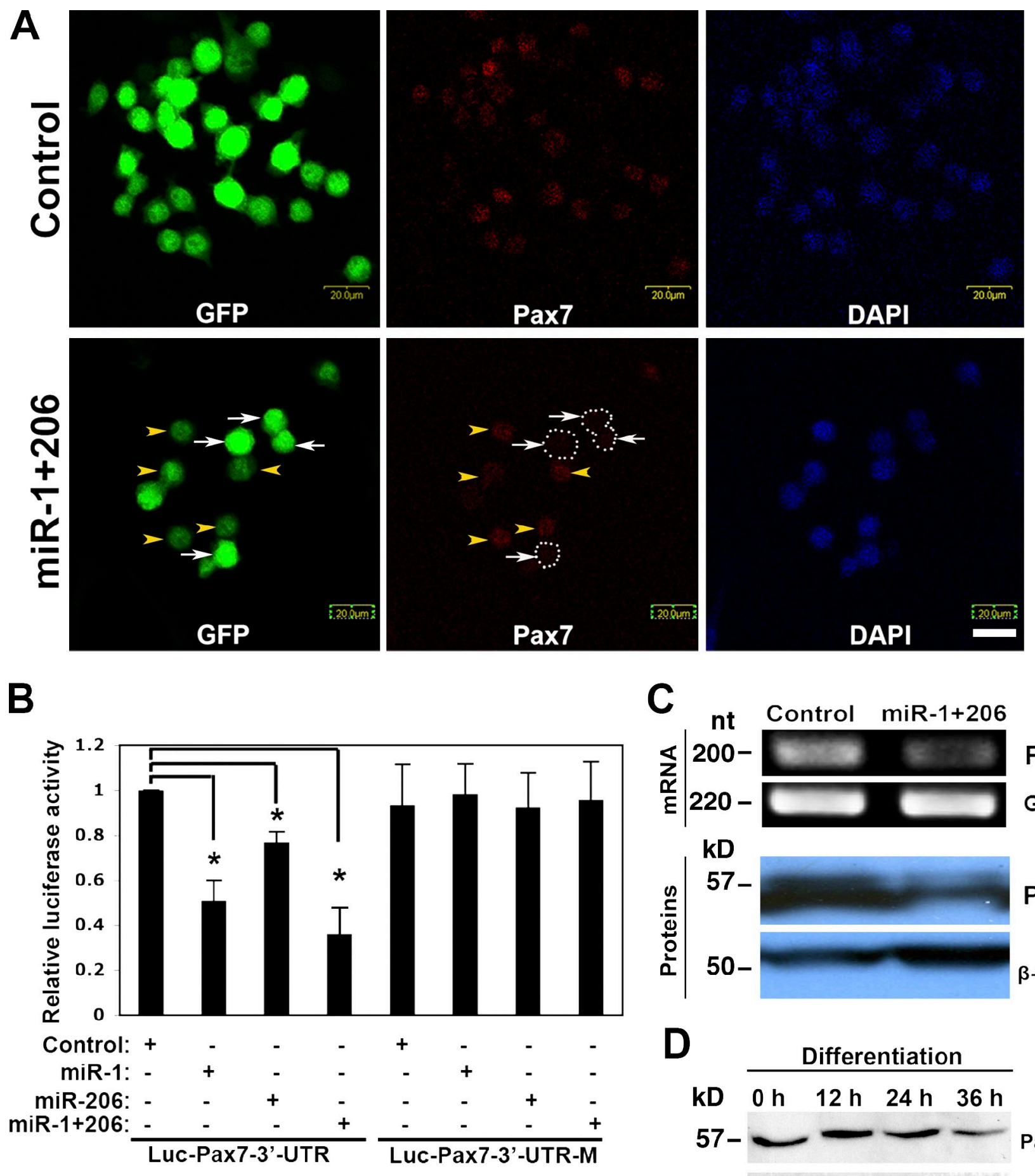

C

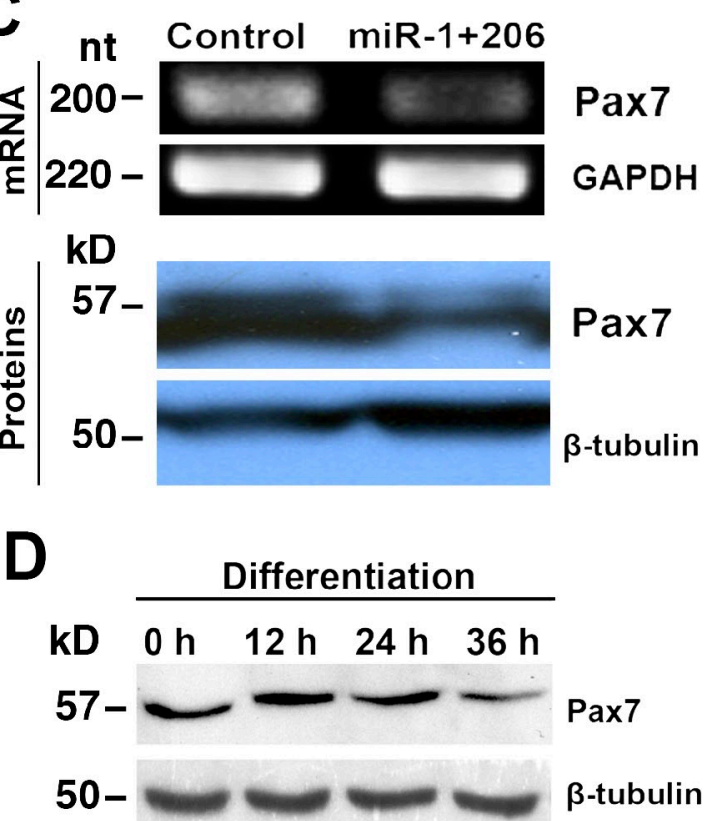

Figure 5. Pax7 is a direct regulatory target of miR-1 and miR-206. (A) Confocal microscopic images of satellite cell colonies infected with retroviral vector expressing GFP-miR-1 and miR-206 or control (GFP only). Note that the expression of Pax7 is inversely correlated with the expression of miR-1 +206 (arrows and arrowheads) but not in the control. DAPI-counterstained nuclei. Dotted areas indicate satellite cells with high expression levels of miR-1 and miR-206. Bars, 20 mm. (B) Repression of Pax7 3'-UTR by miR-1 and miR-206. Luciferase reporters were linked with Pax7 3'-UTRs containing either putative miR-1/miR-206-binding sites (Luc-Pax7-3'-UTR) or mutated miR-1- and miR-206-binding sites (Luc-Pax7-3'-UTR-M). miR-1, miR-206, or miR-1+206 plasmids were cotransfected with luciferase-UTR constructs, and luciferase activity was determined. miR-208 (control) was used to serve as a control for the specificity of miRNA. Data represent the mean \pm SD from three independent experiments. ${ }^{*}, P<0.05$. (C) RT-PCR (top) and Western blot (bottom) analyses of Pax7 mRNA and protein expression in satellite cells infected with retroviral vectors expressing miR-1+206 or a control GFP. GAPDH and $\beta$-tubulin served as controls for loading. nt, nucleotide. (D) Western blot analyses of Pax7 protein expression in satellite cells after being switched to the differentiation condition at the indicated time points. $\beta$-Tubulin served as a loading control. 


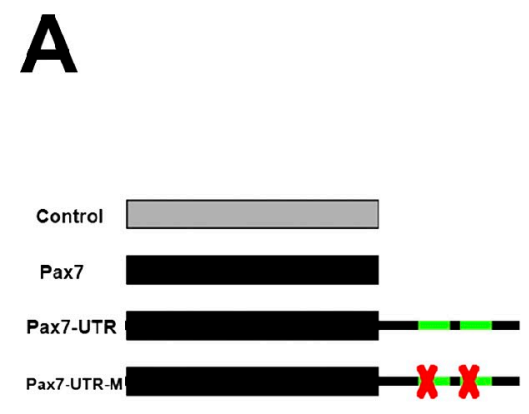

D
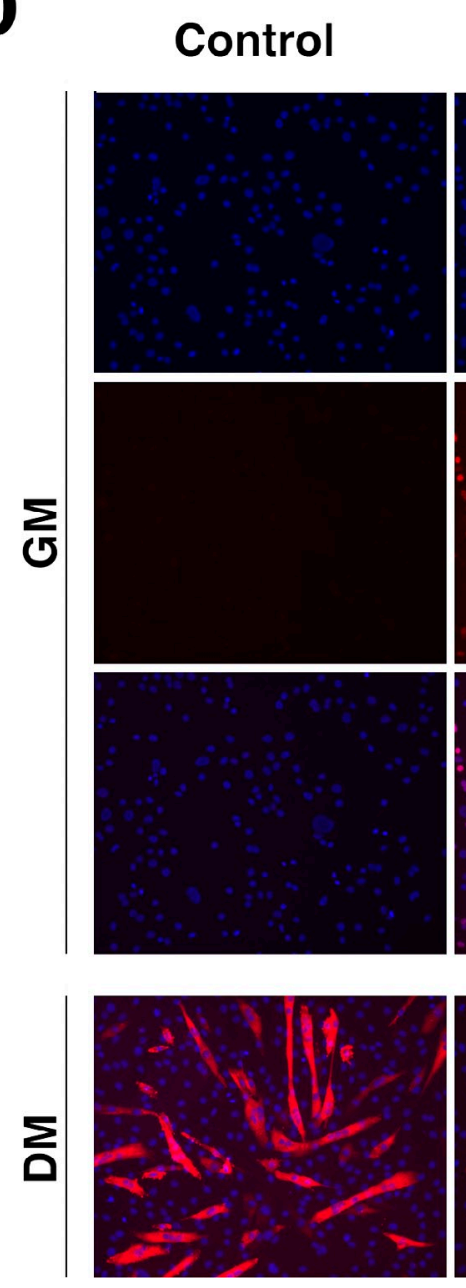
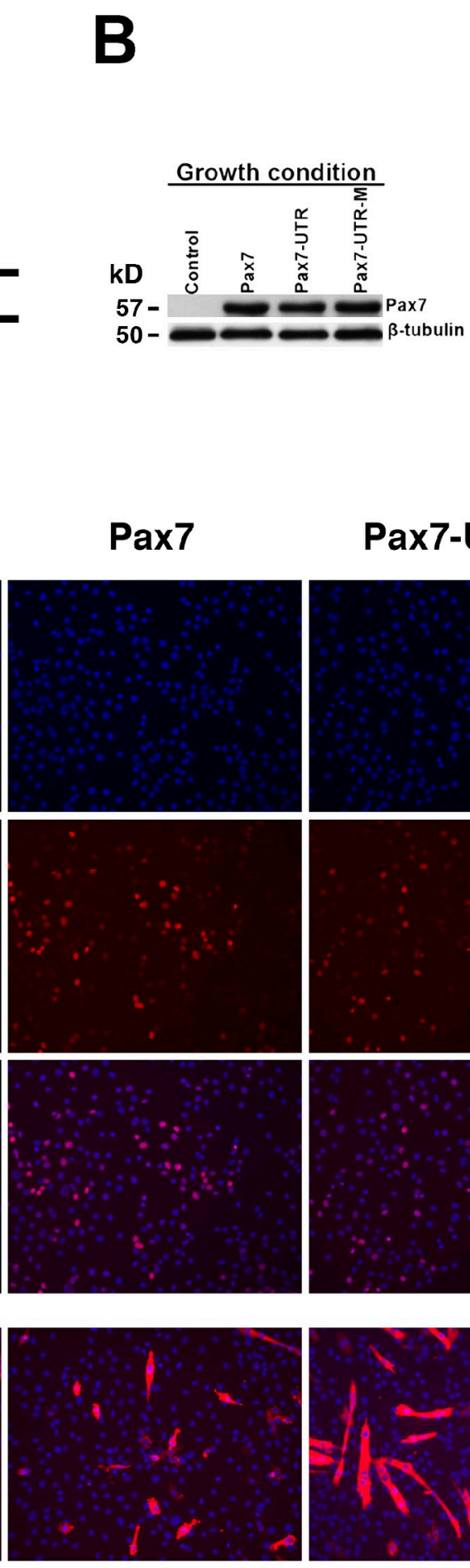

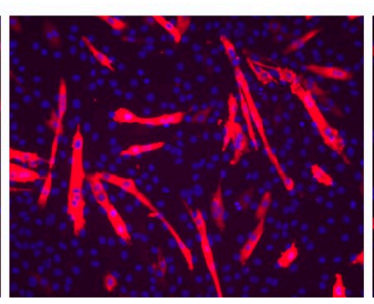

\section{Pax7-UTR}
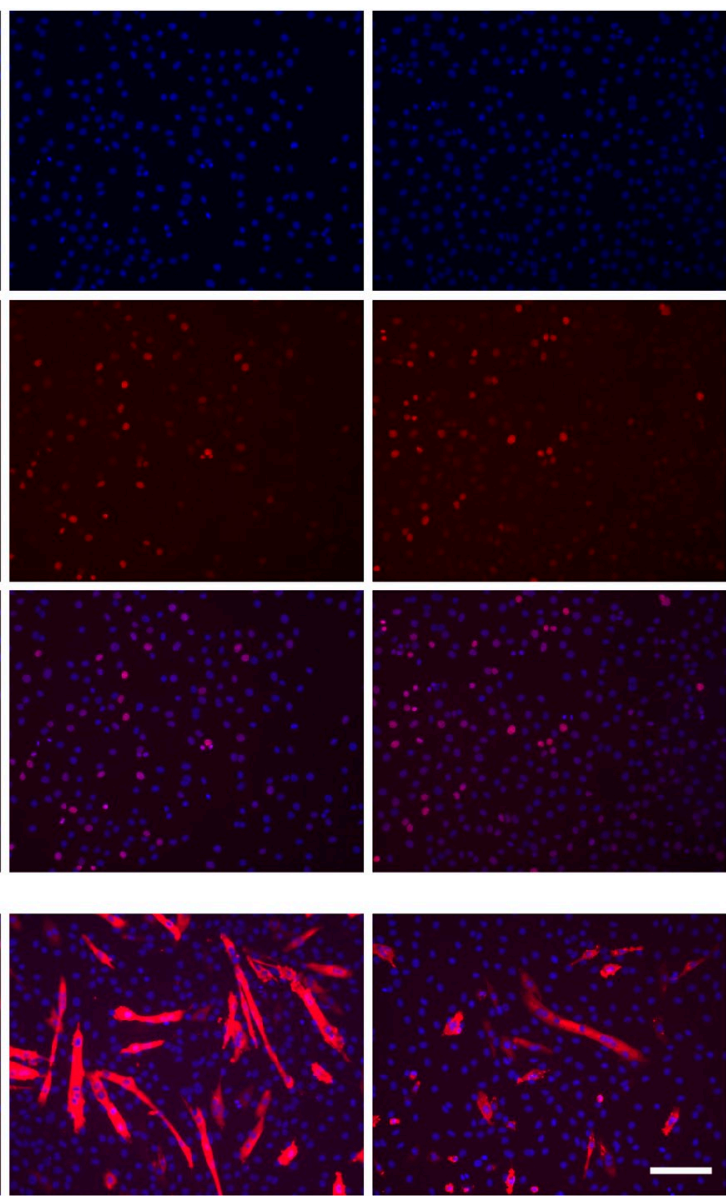

Merge

DAPI

Flag-

Pax7

\section{DAPI}

MyHC

Figure 6. Functional significance of miR-1- and miR-206-mediated repression of Pax7 during myoblast differentiation. (A) Scheme of expression constructs including a control plasmid, Pax7 ORF only (Pax7), Pax7 with its 3'-UTR containing two miR-1- and miR-206-binding sites (Pax7-UTR), or with the two miR-1- and miR-206-binding sites mutated (Pax7-UTR-M). (B) Western blot analyses of Pax7 protein expression in skeletal muscle C2C12 myoblasts stably transfected with control, Pax7, Pax7-UTR, or Pax7-UTR-M expression constructs under growth condition. $\beta$-Tubulin served as a loading control. (C) Expression of Pax7 and other myogenic markers in skeletal muscle C2C12 myoblasts stably transfected with control, Pax7, Pax7-UTR, or Pax7-UTR-M expression constructs under a differentiation condition (36 h after switched to DM). (top) RT-PCR analyses using the indicated primers. GAPDH served as a loading control. (bottom) Western blot analyses using antibodies for Pax7, myogenin, and MyHC. $\beta$-Tubulin served as a loading control. nt, nucleotide. (D) Immunofluorescence of skeletal muscle C2C12 myoblasts stably transfected with the indicated Pax7 expression constructs (or control). Cells were either maintained in GM or switched to DM for an additional $48 \mathrm{~h}$. The cells were stained with antibodies against MyHC or anti-Flag antibody for Pax7 expression. DAPI-counterstained nuclei. Bar, $40 \mu \mathrm{m}$. 
switched to the $\mathrm{C} 2 \mathrm{C} 12$ myoblast cell line, which we could stably transfect with the indicated Pax7 expression constructs. Under the growth condition, where miR-1 and miR-206 expression was barely detected in myoblasts, the expression levels of Pax 7 mRNAs and proteins were similar for all three Pax7 constructs (Fig. 6 B). However, under the differentiation condition, in which miR-1 and miR-206 are rapidly induced, the Pax7 protein expression level is significantly lower in Pax7-UTR-transfected cells compared with Pax7- or Pax7-UTR-M-transfected cells (Fig. 6, C and D). Importantly, we did not detect a significant difference in Pax7 mRNA levels when individual Pax7 expression constructs were stably expressed in myoblasts (Fig. 6 C), indicating that miR-1 and miR-206 contributed to the inhibition of Pax7 protein expression posttranscriptionally via its $3^{\prime}$-UTR. As expected, under the differentiation condition, stable cell lines with Pax 7 and Pax7-UTR-M expression constructs showed profound inhibition of myoblast differentiation compared with cells that stably express Pax7-UTR, as indicated by a significant decrease in the expression of skeletal muscle differentiation marker genes, including myogenin, skeletal muscle $\alpha$-actin, and MyHC (Fig. 6, C and D). Furthermore, we performed immunofluorescent staining to examine the effects of different forms of Pax7 expression constructs on myoblast differentiation. Consistently, myoblasts stably transfected with Pax7 or Pax7-UTR-M expression constructs displayed much less MyHC expression. In contrast, myoblasts stably transfected with the Pax7-UTR expression construct had comparable expression of MyHC with the control (Fig. 6 D), indicating that miR-1- and miR-206mediated repression of Pax 7 expression facilitates cell differentiation. Collectively, these data demonstrate that down-regulation of Pax 7 by miR-1 and miR-206 is functionally significant for the progression of skeletal muscle progenitor cell differentiation.

\section{Discussion}

In this study, we reveal a critical role of miR-1 and miR-206 in the repression of the proliferation of skeletal muscle satellite cells and their derived myogenic progenitor cells. We found that miR-1 and miR-206 are sharply up-regulated during satellite cell differentiation while strikingly decreased during skeletal muscle regeneration. Furthermore, we showed that premature overexpression of miR-1 and miR-206 restricts the proliferative potential of satellite cells and accelerates their myogenic differentiation. Conversely, satellite cell proliferation is increased when miR-1 and miR-206 are knocked down in skeletal muscle in vivo. Furthermore, we identified Pax7 as one of the regulatory targets of miR-1 and miR-206 during satellite cell proliferation and differentiation. We showed that down-regulation of Pax7 by these two miRNAs is crucial for proper muscle progenitor cell differentiation. Our observation that miR-1 and miR-206 facilitate satellite cell differentiation by limiting Pax7 expression implies that miRNAs may play a key role in accelerating the transition from cell proliferation to differentiation. Our conclusion is consistent with a recent study in which miR-203 was shown to promote skin progenitor cell differentiation by repressing the expression of P63, a key transcription factor for skin stem cell fate maintenance (Yi et al., 2008). It will be interesting to determine whether similar miRNA-mediated gene regulation mechanisms exist in other adult stem cells, such as adult neural stem cells and hematopoietic stem cells.

Recently, it was reported that the myogenic regulatory factors MyoD and myogenin inhibit the expression of Pax7 in skeletal muscle primary myoblasts during differentiation (Olguin et al., 2007). However, the molecular mechanism underlying this observation was not well defined. Our experiments, in which miR-1 and miR-206 repress Pax7 protein expression in differentiating muscle progenitor cells, offer an explanation. Pax7 is expressed in undifferentiated satellite cells and is required for the initial activation of Myf5 and MyoD when satellite cells are induced to differentiate and become myogenic progenitor cells. Activated MyoD in satellite cell-derived myogenic progenitor cells will then turn on miR-1 and miR-206 (Rao et al., 2006; Rosenberg et al., 2006). As a result, miR-1 and miR-206 will repress Pax7 posttranscriptionally. Given the essential dual roles of Pax7 in satellite cell self-renewal and myogenic terminal differentiation inhibition, we suggest that the repression of Pax7 protein levels in activated satellite cellderived myogenic progenitor cells by miR-1 and miR-206 could be one of the major mechanisms through which miRNAs regulate satellite cell transition between self-renewal and differentiation (Fig. 7).

We and others previously demonstrated that miR-1 and miR-206 promote skeletal muscle terminal differentiation (Chen et al., 2006; Kim et al., 2006; Rosenberg et al., 2006; Williams et al., 2009). One of the miR-1 regulatory targets that mediates miRNA function in myoblasts is HDAC4, an inhibitor of muscle differentiation. HDAC4 was also shown repressed by miR-206 (Lu et al., 2000; McKinsey et al., 2000; Chen et al., 2006; Williams et al., 2009). In this study, we further show that miR-1 and miR-206 repress transcription factor $\operatorname{Pax} 7$, therefore conferring robustness to the gene program transition from proliferation to differentiation in satellite cells. Interestingly, both miR-1 and miR-206 were sharply down-regulated in injured skeletal muscle, presumably to allow active satellite cell proliferation and regeneration. This study, together with our previous study (Chen et al., 2006), supports the view that miRNAs may regulate multiple mRNA targets that encode proteins with related functions (Leung and Sharp, 2007). A recent study showed that miR-27 represses the expression level of Pax3, another important transcription regulator for satellite cells and myogenic progenitor cells, thereby enhancing the myogenic differentiation program (Crist et al., 2009). It will be important to identify and study additional miR-1 and miR-206 regulatory targets in skeletal muscle, which will be essential to further our understanding of the molecular mechanisms of miRNA function. Intriguingly, the expression of miR-133 was also found to be increased in differentiated satellite cells and decreased in injured skeletal muscle, similar to the expression patterns of miR-1 and miR-206. We and others have reported that miR-1 and miR-133 are cotranscribed in cardiac and skeletal muscle on a polycistronic primary transcript. Unlike miR-1, which strongly promotes myoblast differentiation, miR-133 inhibits myoblast differentiation and enhances proliferation (Chen et al., 2006). Similar observations were also reported in embryonic stem cells 


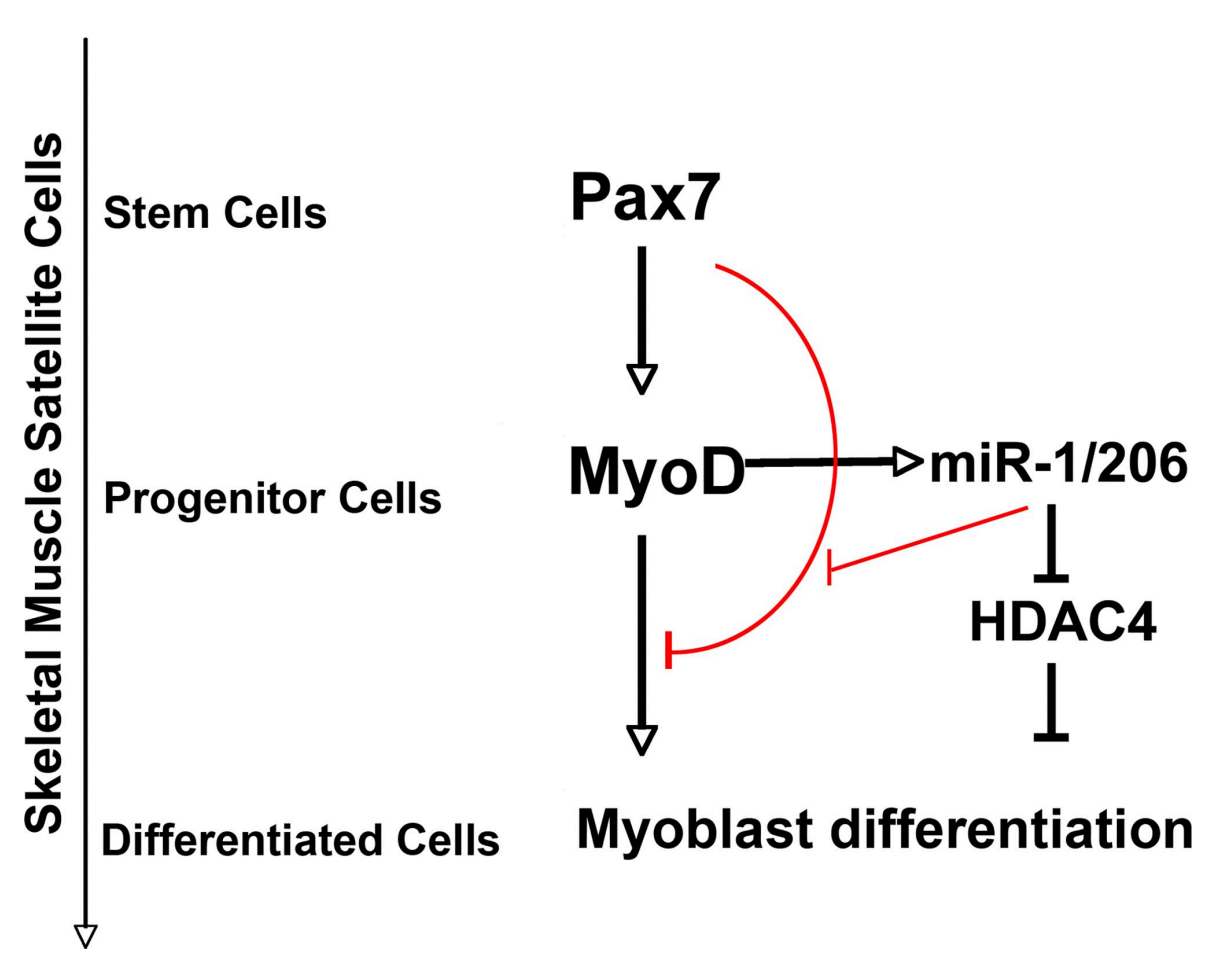

Figure 7. Model of miR-1- and miR-206mediated repression of Pax7 for satellite cell differentiation. Pax7 has multiple functions in satellite cell fate determination. One such role is to specify satellite cells into myogenic fate while preventing their precocious differentiation. Upon the initiation of myogenic differentiation, satellite cell-derived myogenic progenitor cells will start to express myogenic transcription factors, including MyoD, which, in turn, will activate the expression of miR-1 and miR-206. miR-1 and miR-206 potently enhance the myogenic program by limiting and refining the expression of Pax7 in myogenic progenitor cells and myoblasts in addition to repressing HDAC4 (Chen et al., 2006), thereby conferring robustness to the gene program switch from proliferation to differentiation.

that were induced to differentiate into cardiomyocytes (Ivey et al., 2008). It will be important to determine whether miR-133 affects satellite cell proliferation and differentiation processes, and if so, investigate the downstream regulatory targets that mediate such function. In addition, it will be interesting to explore whether similar miR-1 regulatory targets and molecular mechanisms exist in cardiomyocytes, where miR-1 is also highly expressed.

In summary, our findings demonstrate that miR-1 and miR-206 regulate the transition of skeletal muscle satellite cells from proliferation to differentiation. They do so, at least partially, by limiting and refining the expression of important genes that are responsible for the maintenance of adult stem cells in an undifferentiated, self-renewing state. In this manner, miRNAs confer robustness to participate in a feed-forward genetic circuit that reinforces satellite cell commitment from self-renewal to myogenic differentiation. Therefore, miRNAs could be therapeutic tools and targets for human skeletal muscle disease.

\section{Materials and methods}

\section{Mice, satellite cell isolations, and cell cultures}

Mice carrying the Dicer floxed allele (Dicer ${ }^{\text {flox/flox}}$ ) were described previously (Murchison et al., 2005; Chen et al., 2008). Single fibers and associated satellite cells were prepared from EDL muscles as described previously (Rosenblatt et al., 1995; Conboy and Rando, 2002; Shefer and YablonkaReuveni, 2005; Shinin et al., 2006). Primary isolated satellite cells were plated on collagen-coated dishes (Roche) in Ham's F-10 medium (Invitrogen) containing 20\% FBS (Sigma-Aldrich), 1\% penicillin/strep, and fed with $5.0 \mathrm{ng} / \mathrm{ml}$ bFGF (Invitrogen). The identity of satellite cells was determined by the expression of Pax7 proteins. Satellite cell differentiation was induced culturing in $\mathrm{F}-10$ with $2 \%$ horse serum lacking bFGF or FBS as described previously (Frock et al., 2006).

For satellite cell colony formation assays, isolated satellite cells from single myofibers were plated on poly-D-lysine-coated dishes (Sigma-Aldrich) at $\sim 100$ cells $/ \mathrm{cm}^{2}$ for overnight culture. Satellite cells were infected by retroviruses and cultured overnight before selection using puromycin at
$10 \mu \mathrm{g} / \mathrm{ml}$ concentration. GFP-positive cells and single cell-derived colonies were counted at 18,40 , or $72 \mathrm{~h}$ after the infections.

$\mathrm{C} 2 \mathrm{C} 12$ myoblasts were maintained at subconfluent densities in DME supplemented with 20\% FBS (GM). Myogenic differentiation was induced by changing subconfluent cells to DME containing $2 \%$ heat-inactivated horse serum (DM; Chen et al., 2006). To examine the effect of Pax7 expression on myoblast differentiation, $\mathrm{C} 2 \mathrm{C} 12$ myoblasts were transfected with control, Pax7, Pax7-UTR, or Pax7-UTR-M expression constructs and cultured for $12 \mathrm{~h}$ under growth condition after transfection. They were then selected using puromycin at $10 \mu \mathrm{g} / \mathrm{ml}$ for $7 \mathrm{~d}$. Stable cell lines were maintained on GM plus $5 \mu \mathrm{g} / \mathrm{ml}$ puromycin. The expression of Pax7 and myogenic markers was examined using RT-PCR and/or Western blot analyses. The stable cell lines harboring different Pax 7 expression constructs were switched to DM for $36 \mathrm{~h}$ before immunostaining or Western blot analyses.

Generation of adenoviral vectors, retroviral vectors, and cell infection Ad-Cre, Ad-LacZ, and Ad-GFP adenoviruses were provided by the University of North Carolina vector core. Ad-miR-1, Ad-miR-206, and Ad-miR-1/ miR-206 vectors were generated using standard molecular biology techniques. High-titer viruses were prepared as described previously (He et al., 1998) and purified using ViraBind Adenovirus Purification kit (Cell Biolabs, Inc.). For cell transfection, satellite cells were cultured for $2 \mathrm{~d}$ in $G M$ in the presence of bFGF. They were infected with adenoviruses at $37^{\circ} \mathrm{C}$ at a multiplicity of infection of 20-80 for $12 \mathrm{~h}$. Cells were maintained on GM for 2-3 additional days before immunofluorescent staining. Alternatively, cells were induced to differentiate in DME medium with $2 \%$ horse serum for the duration of the time indicated in Figs. 1-7. Myogenesis was analyzed by immunostaining, RT-PCR, or Western blot analysis with indicated markers.

To generate retroviral miR-1, miR-206, and miR-1/miR-206 constructs, the murine stem cell virus vector (MaRX IVfPuro) was modified to carry splicing donor and splicing acceptor sequences where miRNA precursor sequences were inserted (provided by S. Hammond, University of North Carolina at Chapel Hill, Chapel Hill, NC; Fig. S2). The retroviral vectors were generated using standard molecular biology techniques according to the manufacturer's recommendation. 293 lupus erythematosus cells were transfected with $6 \mu \mathrm{g}$ retroviral vectors, $3 \mu \mathrm{g}$ envelope plasmids, and 3 pg gag-pol plasmids (Fugene6; Roche). Viral supernatants from 293LE cells were filtered through a $0.2 \mathrm{\mu m}$ syringe and subsequently used to infect satellite cells as described previously (Springer and Blau, 1997). In brief, growing satellite cells were immersed in viral supernatant in the presence of $20 \% \mathrm{FBS}, 8 \mathrm{\mu g} / \mathrm{ml}$ polybrene, and $5.0 \mathrm{ng} / \mathrm{ml} \mathrm{bFGF}$, returned to the $\mathrm{CO}_{2}$ incubator for $15 \mathrm{~min}$, and the dish was centrifuged at $32^{\circ} \mathrm{C}$ for 30 min at $1,100 \mathrm{~g}$. After centrifugation, satellite cells were replaced with fresh GM containing $20 \% \mathrm{FBS}$ and $5.0 \mathrm{ng} / \mathrm{ml}$ bFGF and cultured 
overnight before selection using puromycin at $10 \mu \mathrm{g} / \mathrm{ml}$ concentration. Satellite cells were maintained on selection medium for an additional $4 \mathrm{~d}$ before analysis.

\section{miRNA microarray, Northern blot, and RT-PCR analysis}

miRNA microarray, Northern blot, and RT-PCR assays were performed as described previously (Chen et al., 2006). $5 \mu \mathrm{g}$ and $10 \mu \mathrm{g}$ total RNAs isolated from skeletal muscle satellite cells were used for microarray and Northern blot assays, respectively.

\section{Proliferation and differentiation assay, immunohistochemistry, and Western blot analysis}

To measure cell proliferation, satellite cells infected with adenoviruses were maintained on GM for $48 \mathrm{~h}$, pulsed with $10 \mu \mathrm{M}$ BrdU (Sigma-Aldrich) for $1.5 \mathrm{~h}$, and fixed for immunostaining using anti-BrdU antibody at $1: 1,000$ dilution (A21300; Invitrogen). To examine the expression level of endogenous Pax7 in satellite cells after overexpression of miR-1 and miR-206, retroviral miR-1- and miR-206-infected satellite cells were cultured under $10 \mu \mathrm{g} / \mathrm{ml}$ puromycin selection for $4 \mathrm{~d}$ before immunostaining or Western blotting using Pax7 antibody at 1:100 dilution (Developmental Studies Hybridoma Bank [DSHB], University of lowa, lowa City, IA). To examine myogenic differentiation of satellite cells after the removal of bFGF and FBS, retroviral miR-1-and miR-206-infected cells, induced to differentiate at different time points, were fixed for immunostaining using the MF2O antibody, which recognizes MyHC proteins (DSHB, University of lowa). The following antibodies and conditions were used for immunostaining and Western blot analyses for $\mathrm{C} 2 \mathrm{C} 12$ myoblasts: MF20, 1:20 dilution in immunostaining and 1:100 dilution in Western blotting; myogenin (Santa Cruz Biotechnology, Inc.), 1:200 dilution; Flag (F7425; Sigma-Aldrich), rabbit polyclonal at 1:400 dilution.

Histological processing and immunochemical staining of skeletal muscle tissues were performed as described previously (Yan et al., 2003). Skeletal muscle tissues were embedded in optimal cutting temperature compound before $10 \mu \mathrm{m}$ cyrosectioning (Chen et al., 2008). For costaining of Pax7 and BrdU, M.O.M. blocking kit (Vector Laboratories) and avidin/ biotin blocking kit (Vector Laboratories) were used to stain muscle sections. The primary antibodies used were Pax7 (DSHB, University of lowa) and biotin-BrdU (Invitrogen). The secondary antibodies used were avidin-FITC and Alex Fluor 594 goat anti-mouse lgG (Invitrogen). All images were acquired by a camera (UFX-DX; Nikon) mounted on an inverted (TE2000; Nikon) or upright fluorescence microscope (Microphot-SA; Nikon). Digital fluorescent images were captured at room temperature with a Plan Fluor

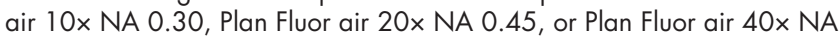
0.60 objective lens using the least possible exposure to minimize bleaching. Confocal microscopic images (Figs. 3-5 and Fig. S3) were captured using a confocal laser-scanning microscope (FV 500; Olympus) with a Plan Apochromat $63 \times$ NA 1.40 oil objective lens (Microscopy Service Laboratory, University of North Carolina). The images were processed using SPOT (version 3.5.4 for MacOS; Diagnostic Instruments, Inc.) software and were scaled down and cropped in Photoshop (Adobe) to prepare the final figures.

\section{TUNEL assay}

Satellite cells carrying Dicer flox/flox alleles were isolated using the same protocol as described for wild-type satellite cell isolation. Isolated Dicerflox/flox satellite cells were infected with Ad-Cre or Ad-LacZ (as a control) for $12 \mathrm{~h}$. Ad-LacZ- or Ad-Cre-infected Dicer ${ }^{\text {flox/flox }}$ satellite cells were cultured under growth condition for an additional $72 \mathrm{~h}$ and switched to differentiation condition for $5 \mathrm{~h}$ before TUNEL assay. TUNEL assays were performed using ApopTaq Fluorescein in situ Apoptosis Detection kit (Millipore) according to the manufacturer's instructions.

\section{Antagomir synthesis and injection}

Antagomir-1, mut-antagomir-1, antagomir-206, and mut-antagomir-206 were designed and synthesized (Thermo Fisher Scientific) as described previously (Krutzfeldt et al., 2005). The antagomir-1 sequence was $5^{\prime}-{ }^{*} \mathrm{~m}$ $A^{*} m A m U m A m C m A m U m A m C m U m U m C m U m U m U m A m C m A m U * m U^{*} m C$ ${ }^{*} \mathrm{mC} \mathrm{C}^{*} \mathrm{mAChl}-3$ ', and the mut-antagomir-1 sequence was $5^{\prime}-{ }^{*} \mathrm{~mA} \mathrm{~A}^{*} \mathrm{mAmU}$ $m c m C m A m U m g m C m U m c m C m U m U m U m A m C m A m g * m U * m C * m C * m A C$ hl-3'. The antagomir-206 sequence was $5^{\prime}-{ }^{*} \mathrm{~mA}^{*} \mathrm{mCmCmAmCmAmCmA}$ $\mathrm{mCmUmUmCmCmUmUmAmCmAmU}{ }^{*} \mathrm{mU}^{*} \mathrm{mC}^{*} \mathrm{mC} \mathrm{m}^{*} \mathrm{mAChl}-3^{\prime}$, and the mut-antagomir-206 sequence was $5^{\prime}-{ }^{*} \mathrm{~mA}^{*} \mathrm{mCmCmcmCmAmCmgmCmU}$ $\mathrm{mcmCmCmUmUmAmCmAmg}{ }^{*} \mathrm{mU}^{*} \mathrm{mC}^{*} \mathrm{mC}^{*} \mathrm{mAChl}-3^{\prime}$. Lowercase letters represent the mismatched sequence, " $\mathrm{m}$ " represents the 2'-O-methyl-modified nucleotide, "*" indicate a phosphorothioate linkage, and "Chl" indicates cholesterol linked through a hydroxyprolinol linkage. IP or intramuscular injection was performed on postnatal day 3 C57BL/6J mice. Antagomirs or controls were administrated twice at a dose of $80 \mathrm{mg} / \mathrm{kg}$ body weight in $0.01 \mathrm{ml} /$ injection on every other day. Animals were sacrificed $24 \mathrm{~h}$ after the last injection for experimental analysis.

\section{Online supplemental material}

Fig. S1 shows the isolation and phenotypic characterization of skeletal muscle satellite cells. Fig. S2 shows that Dicer-depleted satellite cells exhibit higher rate of apoptosis in response to serum withdrawal. Fig. S2 also shows miR-1 sensor and retroviral vector expressing miR-1 and miR-206. Fig. S3 shows increased Pax7-positive satellite cells in antagomirs-1and -206-treated skeletal muscle. Fig. S4 shows that miR-1 and miR-206 inhibit endogenous Pax7 protein expression. Fig. S5 shows the $3^{\prime}$-UTR of Pax7 transcript containing two binding sites for miR-1 and miR-206. Online supplemental material is available at http://www.jcb.org/cgi/ content/full/jcb.200911036/DC1.

We thank members of the Wang laboratory for discussion and support, Xiaoyun Hu for excellent technical support, Kirk McNaughton for histology, Scott Hammond for help with miRNA microarrays, and Gregory Hannon (Cold Spring Harbor Laboratory) for Dicer-flox mice. We thank Bill Pu, Mark Majesky, and Xuefei Wang for careful reading of the manuscript.

This work was supported by the March of Dimes Birth Defect Foundation, the National Institutes of Health, and the Muscular Dystrophy Association. Z. Deng is supported by the Chinese National Natural Science Foundation Igrant 3077221 1). D.Z. Wang is an Established Investigator of the American Heart Association.

Submitted: 6 November 2009

Accepted: 6 August 2010

\section{References}

Bernstein, E., A.A. Caudy, S.M. Hammond, and G.J. Hannon. 2001. Role for a bidentate ribonuclease in the initiation step of RNA interference. Nature. 409:363-366. doi:10.1038/35053110

Bernstein, E., S.Y. Kim, M.A. Carmell, E.P. Murchison, H. Alcorn, M.Z. Li, A.A. Mills, S.J. Elledge, K.V. Anderson, and G.J. Hannon. 2003. Dicer is essential for mouse development. Nat. Genet. 35:215-217. doi:10.1038/ng1253

Buckingham, M. 2007. Skeletal muscle progenitor cells and the role of Pax genes. C. R. Biol. 330:530-533. doi:10.1016/j.crvi.2007.03.015

Callis, T.E., and D.Z. Wang. 2008. Taking microRNAs to heart. Trends Mol. Med. 14:254-260. doi:10.1016/j.molmed.2008.03.006

Chen, J.F., E.M. Mandel, J.M. Thomson, Q. Wu, T.E. Callis, S.M. Hammond, F.L. Conlon, and D.Z. Wang. 2006. The role of microRNA-1 and microRNA-133 in skeletal muscle proliferation and differentiation. Nat. Genet. 38:228-233. doi:10.1038/ng1725

Chen, J.F., E.P. Murchison, R. Tang, T.E. Callis, M. Tatsuguchi, Z. Deng, M. Rojas, S.M. Hammond, M.D. Schneider, C.H. Selzman, et al. 2008. Targeted deletion of Dicer in the heart leads to dilated cardiomyopathy and heart failure. Proc. Natl. Acad. Sci. USA. 105:2111-2116. doi: 10.1073/pnas.0710228105

Clegg, C.H., T.A. Linkhart, B.B. Olwin, and S.D. Hauschka. 1987. Growth factor control of skeletal muscle differentiation: commitment to terminal differentiation occurs in G1 phase and is repressed by fibroblast growth factor. J. Cell Biol. 105:949-956. doi:10.1083/jcb.105.2.949

Conboy, I.M., and T.A. Rando. 2002. The regulation of Notch signaling controls satellite cell activation and cell fate determination in postnatal myogenesis. Dev. Cell. 3:397-409. doi:10.1016/S15345807(02)00254-X

Crist, C.G., D. Montarras, G. Pallafacchina, D. Rocancourt, A. Cumano, S.J. Conway, and M. Buckingham. 2009. Muscle stem cell behavior is modified by microRNA-27 regulation of Pax3 expression. Proc. Natl. Acad. Sci. USA. 106:13383-13387. doi:10.1073/pnas.0900210106

Eisenberg, I., A. Eran, I. Nishino, M. Moggio, C. Lamperti, A.A. Amato, H.G. Lidov, P.B. Kang, K.N. North, S. Mitrani-Rosenbaum, et al. 2007. Distinctive patterns of microRNA expression in primary muscular disorders. Proc. Natl. Acad. Sci. USA. 104:17016-17021. doi:10.1073/pnas .0708115104

Frock, R.L., B.A. Kudlow, A.M. Evans, S.A. Jameson, S.D. Hauschka, and B.K. Kennedy. 2006. Lamin A/C and emerin are critical for skeletal muscle satellite cell differentiation. Genes Dev. 20:486-500. doi:10 $.1101 / \mathrm{gad} .1364906$ 
Grez, M., E. Akgün, F. Hilberg, and W. Ostertag. 1990. Embryonic stem cell virus, a recombinant murine retrovirus with expression in embryonic stem cells. Proc. Natl. Acad. Sci. USA. 87:9202-9206. doi:10.1073/pnas 87.23.9202

Griffiths-Jones, S. 2004. The microRNA Registry. Nucleic Acids Res. 32:D109D111. doi:10.1093/nar/gkh023

Grishok, A., A.E. Pasquinelli, D. Conte, N. Li, S. Parrish, I. Ha, D.L. Baillie, A. Fire, G. Ruvkun, and C.C. Mello. 2001. Genes and mechanisms related to RNA interference regulate expression of the small temporal RNAs that control C. elegans developmental timing. Cell. 106:2334. doi:10.1016/S0092-8674(01)00431-7

He, T.C., S. Zhou, L.T. da Costa, J. Yu, K.W. Kinzler, and B. Vogelstein. 1998 A simplified system for generating recombinant adenoviruses. Proc. Natl. Acad. Sci. USA. 95:2509-2514. doi:10.1073/pnas.95.5.2509

Ivey, K.N., A. Muth, J. Arnold, F.W. King, R.F. Yeh, J.E. Fish, E.C. Hsiao, R.J. Schwartz, B.R. Conklin, H.S. Bernstein, and D. Srivastava. 2008. MicroRNA regulation of cell lineages in mouse and human embryonic stem cells. Cell Stem Cell. 2:219-229. doi:10.1016/j.stem.2008.01.016

Jaenisch, R., and R. Young. 2008. Stem cells, the molecular circuitry of pluripotency and nuclear reprogramming. Cell. 132:567-582. doi:10.1016/ j.cell.2008.01.015

Kim, H.K., Y.S. Lee, U. Sivaprasad, A. Malhotra, and A. Dutta. 2006. Musclespecific microRNA miR-206 promotes muscle differentiation. J. Cell Biol. 174:677-687. doi:10.1083/jcb.200603008

Krützfeldt, J., N. Rajewsky, R. Braich, K.G. Rajeev, T. Tuschl, M. Manoharan, and M. Stoffel. 2005. Silencing of microRNAs in vivo with 'antagomirs'. Nature. 438:685-689. doi:10.1038/nature04303

Kuang, S., S.B. Chargé, P. Seale, M. Huh, and M.A. Rudnicki. 2006. Distinct roles for Pax7 and Pax3 in adult regenerative myogenesis. J. Cell Biol. 172:103-113. doi:10.1083/jcb.200508001

Kuang, S., M.A. Gillespie, and M.A. Rudnicki. 2008. Niche regulation of muscle satellite cell self-renewal and differentiation. Cell Stem Cell. 2:22-31. doi:10.1016/j.stem.2007.12.012

Leung, A.K., and P.A. Sharp. 2007. microRNAs: a safeguard against turmoil? Cell. 130:581-585. doi:10.1016/j.cell.2007.08.010

Lu, J., T.A. McKinsey, C.L. Zhang, and E.N. Olson. 2000. Regulation of skeletal myogenesis by association of the MEF2 transcription factor with class II histone deacetylases. Mol. Cell. 6:233-244. doi:10.1016/ S1097-2765(00)00025-3

McFarlane, C., A. Hennebry, M. Thomas, E. Plummer, N. Ling, M. Sharma, and R. Kambadur. 2008. Myostatin signals through Pax7 to regulate satellite cell self-renewal. Exp. Cell Res. 314:317-329.

McKinsey, T.A., C.L. Zhang, J. Lu, and E.N. Olson. 2000. Signal-dependent nuclear export of a histone deacetylase regulates muscle differentiation. Nature. 408:106-111. doi:10.1038/35040593

Miller, A.D., and G.J. Rosman. 1989. Improved retroviral vectors for gene transfer and expression. Biotechniques. 7:980-982: 984-986: 989-990.

Montarras, D., J. Morgan, C. Collins, F. Relaix, S. Zaffran, A. Cumano, T. Partridge, and M. Buckingham. 2005. Direct isolation of satellite cells for skeletal muscle regeneration. Science. 309:2064-2067. doi:10 $.1126 /$ science. 1114758

Morgan, J.E., and T.A. Partridge. 2003. Muscle satellite cells. Int. J. Biochem Cell Biol. 35:1151-1156. doi:10.1016/S1357-2725(03)00042-6

Murchison, E.P., J.F. Partridge, O.H. Tam, S. Cheloufi, and G.J. Hannon. 2005 Characterization of Dicer-deficient murine embryonic stem cells. Proc. Natl. Acad. Sci. USA. 102:12135-12140. doi:10.1073/pnas.0505479102

Olguin, H.C., and B.B. Olwin. 2004. Pax-7 up-regulation inhibits myogenesis and cell cycle progression in satellite cells: a potential mechanism for self-renewal. Dev. Biol. 275:375-388. doi:10.1016/j.ydbio.2004.08.015

Olguin, H.C., Z. Yang, S.J. Tapscott, and B.B. Olwin. 2007. Reciprocal inhibition between Pax7 and muscle regulatory factors modulates myogenic cell fate determination. J. Cell Biol. 177:769-779. doi:10.1083/jcb.200608122

Oustanina, S., G. Hause, and T. Braun. 2004. Pax7 directs postnatal renewal and propagation of myogenic satellite cells but not their specification. EMBO J. 23:3430-3439. doi:10.1038/sj.emboj.7600346

Rao, P.K., R.M. Kumar, M. Farkhondeh, S. Baskerville, and H.F. Lodish. 2006. Myogenic factors that regulate expression of muscle-specific microRNAs. Proc. Natl. Acad. Sci. USA. 103:8721-8726. doi:10.1073/pnas .0602831103

Relaix, F., D. Rocancourt, A. Mansouri, and M. Buckingham. 2005. A Pax3/ Pax7-dependent population of skeletal muscle progenitor cells. Nature. 435:948-953. doi:10.1038/nature03594

Relaix, F., D. Montarras, S. Zaffran, B. Gayraud-Morel, D. Rocancourt, S. Tajbakhsh, A. Mansouri, A. Cumano, and M. Buckingham. 2006. Pax3 and Pax7 have distinct and overlapping functions in adult muscle progenitor cells. J. Cell Biol. 172:91-102. doi:10.1083/jcb.200508044
Rosenberg, M.I., S.A. Georges, A. Asawachaicharn, E. Analau, and S.J. Tapscott. 2006. MyoD inhibits Fstl1 and Utrn expression by inducing transcription of miR-206. J. Cell Biol. 175:77-85. doi:10.1083/jcb.200603039

Rosenblatt, J.D., A.I. Lunt, D.J. Parry, and T.A. Partridge. 1995. Culturing satellite cells from living single muscle fiber explants. In Vitro Cell. Dev. Biol. Anim. 31:773-779. doi:10.1007/BF02634119

Rossant, J. 2008. Stem cells and early lineage development. Cell. 132: 527-531. doi:10.1016/j.cell.2008.01.039

Sabourin, L.A., A. Girgis-Gabardo, P. Seale, A. Asakura, and M.A. Rudnicki. 1999. Reduced differentiation potential of primary $\mathrm{MyoD}^{-/-}$myogenic cells derived from adult skeletal muscle. J. Cell Biol. 144:631-643. doi:10 .1083/jcb.144.4.631

Senoo, M., F. Pinto, C.P. Crum, and F. McKeon. 2007. p63 Is essential for the proliferative potential of stem cells in stratified epithelia. Cell. 129:523536. doi:10.1016/j.cell.2007.02.045

Shefer, G., and Z. Yablonka-Reuveni. 2005. Isolation and culture of skeletal muscle myofibers as a means to analyze satellite cells. Methods Mol. Biol. 290:281-304.

Shinin, V., B. Gayraud-Morel, D. Gomès, and S. Tajbakhsh. 2006. Asymmetric division and cosegregation of template DNA strands in adult muscle satellite cells. Nat. Cell Biol. 8:677-687. doi:10.1038/ncb1425

Springer, M.L., and H.M. Blau. 1997. High-efficiency retroviral infection of primary myoblasts. Somat. Cell Mol. Genet. 23:203-209. doi:10 1007/BF02721371

Tatsuguchi, M., H.Y. Seok, T.E. Callis, J.M. Thomson, J.F. Chen, M. Newman, M. Rojas, S.M. Hammond, and D.Z. Wang. 2007. Expression of microRNAs is dynamically regulated during cardiomyocyte hypertrophy. J. Mol. Cell. Cardiol. 42:1137-1141. doi:10.1016/j.yjmcc.2007.04.004

Templeton, T.J., and S.D. Hauschka. 1992. FGF-mediated aspects of skeletal muscle growth and differentiation are controlled by a high affinity receptor, FGFR1. Dev. Biol. 154:169-181. doi:10.1016/0012-1606(92)90057-N

Thum, T., P. Galuppo, C. Wolf, J. Fiedler, S. Kneitz, L.W. van Laake, P.A. Doevendans, C.L. Mummery, J. Borlak, A. Haverich, et al. 2007. MicroRNAs in the human heart: a clue to fetal gene reprogramming in heart failure. Circulation. 116:258-267. doi:10.1161/CIRCULATIONAHA .107 .687947

van Rooij, E., N. Liu, and E.N. Olson. 2008. MicroRNAs flex their muscles. Trends Genet. 24:159-166. doi:10.1016/j.tig.2008.01.007

Wang, Y., R. Medvid, C. Melton, R. Jaenisch, and R. Blelloch. 2007. DGCR8 is essential for microRNA biogenesis and silencing of embryonic stem cell self-renewal. Nat. Genet. 39:380-385. doi:10.1038/ng1969

Williams, A.H., G. Valdez, V. Moresi, X. Qi, J. McAnally, J.L. Elliott, R. BasselDuby, J.R. Sanes, and E.N. Olson. 2009. MicroRNA-206 delays ALS progression and promotes regeneration of neuromuscular synapses in mice. Science. 326:1549-1554. doi:10.1126/science.1181046

Yan, Z., S. Choi, X. Liu, M. Zhang, J.J. Schageman, S.Y. Lee, R. Hart, L. Lin, F.A. Thurmond, and R.S. Williams. 2003. Highly coordinated gene regulation in mouse skeletal muscle regeneration. J. Biol. Chem. 278:88268836. doi:10.1074/jbc.M209879200

Yang, A., R. Schweitzer, D. Sun, M. Kaghad, N. Walker, R.T. Bronson, C. Tabin, A. Sharpe, D. Caput, C. Crum, and F. McKeon. 1999. p63 is essential for regenerative proliferation in limb, craniofacial and epithelial development. Nature. 398:714-718. doi:10.1038/19539

Yi, R., M.N. Poy, M. Stoffel, and E. Fuchs. 2008. A skin microRNA promotes differentiation by repressing 'stemness'. Nature. 452:225-229. doi:10.1038/ nature 06642

Zammit, P.S., J.P. Golding, Y. Nagata, V. Hudon, T.A. Partridge, and J.R. Beauchamp. 2004. Muscle satellite cells adopt divergent fates: a mechanism for self-renewal? J. Cell Biol. 166:347-357. doi:10.1083/jcb.200312007

Zammit, P.S., F. Relaix, Y. Nagata, A.P. Ruiz, C.A. Collins, T.A. Partridge, and J.R. Beauchamp. 2006. Pax7 and myogenic progression in skeletal muscle satellite cells. J. Cell Sci. 119:1824-1832. doi:10.1242/jcs.02908

Zhao, Y., J.F. Ransom, A. Li, V. Vedantham, M. von Drehle, A.N. Muth, T. Tsuchihashi, M.T. McManus, R.J. Schwartz, and D. Srivastava. 2007. Dysregulation of cardiogenesis, cardiac conduction, and cell cycle in mice lacking miRNA-1-2. Cell. 129:303-317. doi:10.1016/j.cell.2007.03.030 